ANUARIo DE ESTUdios MEdievales (AEM)

36/1, enero junio de 2006

pp. 253-294

ISSN 0066-5061

\title{
DIPLOMACIA Y GUERRA EN EL MEDITERRÁNEO MEDIEVAL. LA LIGA VÉNETO-ARAGONESA CONTRA GÉNOVA DE $1351^{1}$
}

\author{
José ViCENTE CABEZUELO PLIEGO \\ Universidad de Alicante
}

Resumen: En enero de 1351 la Corona de Aragón y Venecia firman una alianza militar contra la República de Génova. En este artículo se aborda el análisis de los capítulos de esa alianza, así como de dos embajadas aragonesas a la corte veneciana relativas a la renegociación de aspectos no suficientemente perfilados en los tratos de 1351. Todo ello contextualizado dentro de las relaciones político-comerciales de las potencias mediterráneas en las décadas centrales del siglo XIV.

Palabras clave:Guerra; Diplomacia; Mediterráneo; Venecia

\begin{abstract}
In January 1351, the Crown of Aragon and Venice signed a military treaty against the Republic of Genova. This essay analyses the chapters of this alliance, together with two Offices that the Crown of Aragon sent to the Court of Venice a propos of the renegotiation of a series of aspects that had not been sufficiently contemplated in the treaties of 1351. This analysis will be dealt with in the context of the political and commercial relations that characterised the Great Powers in the Mediterranean area during the XIV century.
\end{abstract}

Keywords: War; Diplomacy; Mediterranean; Vrnice

${ }^{1}$ La base de este texto se corresponde con la conferencia pronunciada en diciembre de 2005 en la Universidad $\mathrm{Ca}^{\prime}$ Foscari deVenecia dentro del seminario titulado Oriente italiano e levante iberico: società e culture mediterranee in contacto. Agradezco a las doctoras Yadira González de Lara, de la Universidad de Alicante, y Roser Salicrú i Lluch, del CSIC (Barcelona) el acercamiento a una bibliografía de difícil acceso para quien esto escribe, así como al profesor Juan Francisco Mesa Sanz, de la Universidad de Alicante, su gentil colaboración en la traducción de algún pasaje en lengua latina. 
1. El camino hacia la guerra y la búsqueda de aliados.- 2. Las negociaciones y el pacto.- 3. La activación de la alianza. Flecos diplomáticos y nuevas embajadas.- 4. Del Egeo al Tirreno: razones de un desencuentro y el final de la colaboración militar.

\section{EL CAMINO HACIA LA GUERRA Y LA BÚSQUEDA DE ALIADOS}

En lo genérico, la presencia italiana en la Corona de Aragón está perfectamente documentada ya en la primera mitad del siglo $\mathrm{XII}^{2}$, cuando se comienza a gestar la situación de privilegio fiscal de algunas de sus repúblicas a cambio de colaboración político-militar con los condes de Barcelona. Desde al menos ese momento las costas orientales ibéricas fueron destino comercial de mercaderes italianos, así como fondeaderos y puntos de abastecimiento de mercancías y vituallas de sus galeras, que realizaban largos viajes hasta Sicilia y Mallorca. La Italia del Norte encontró en estas tierras un paraíso económico que explotar, pues al acopio de materias primas se unía el intercambio de productos manufacturados, reexportados a todo el Mediterráneo Occidental, creándose un circuito cuyo eje se localizaba en el Golfo de Génova con una potente irradiación a Provenza, Languedoc, la península ibérica, tanto el área catalano-valenciana como la castellana, Mallorca, el reino nazarí de Granada, el Norte de África y Sicilia. En esos espacios, la presencia genovesa se constituyó como factor decisivo en la conformación de la aspiración por parte de la república ligur del dominio del Mediterráneo Centro-Occidental y de su mercado. Si bien, tal concurrencia refiere a la Italia tirrénica. De la oriental, la adriática, sabemos menos, tanto en el terreno comercial como en el político. Pero lo cierto es que la falta de conocimientos no es paralela a una ausencia de relaciones, aunque realmente no fuesen abundantes. Uno de esos

${ }^{2}$ María Teresa FERrer I MALlol, Els italians a terres catalanes (segles XII-XV), "Anuario de Estudios Medievales", 10 (1980), pp. 393-467. Con el territorio valenciano la relación es contemporánea en el tiempo, pese a que el área fuese por entonces dominio islámico. Resulta curioso que en 1149 Abu Abd Allah Muhammad Ibn Said, conocido como el Rey Lobo de Valencia, firmase sendos tratados con Pisa y Génova con la intención de promocionar el comercio bilateral al tiempo que de granjearse amigos en Italia con el fin de limitar la colaboración de éstos en las empresas conquistadores de los condes catalanes. David IGUAL LUIS, Valencia e Italia en el siglo XV. Rutas, mercados y hombres de negocios en el espacio económico del Mediterráneo Occidental, Vilareal, 1998, p. 31. 
momentos de contacto se produce a mediados del siglo XIV, cuando la Corona de Aragón y el Común de Venecia, en una coyuntura difícil para ambas potencias, deciden mancomunar intereses, políticos y económicos, frente a un enemigo común, Génova, a través de una alianza militar.

Desde el punto de vista historiográfico la cuestión no es desconocida, pues ya el cronista Zurita a mediados del Quinientos daba cuenta de la liga véneto-aragonesa de mediados del siglo XIV, así como de los resultados de la misma. Y desde esa fecha muchos historiadores la han referido. En el ámbito italiano, entre los autores que han estudiado las guerras vénetogenovesas, uno en particular, Camilo Manfroni, escribía en 1902 un artículo en el que trataba de la cuestión que aquí abordo, aunque desde el observatorio veneciano $^{3}$. Desde esa fecha, principios del siglo XX, la cuestión ha sido tratada con cierta profusión y así en todas las historias de la Serenissima se le dedica algún párrafo ${ }^{4}$. Otro tanto sucede del lado genovés, donde los efectos de la liga firmada entre la República de San Marcos y la Corona de Aragón contra los de San Jorge han sido bien ejemplificados 5 . Sin embargo, en los dominios ibéricos esta relación política pasa prácticamente inadvertida hasta mediados del siglo pasado, en que una historiadora vinculada a una universidad italiana ofreciera un estudio que atendía al asunto que aquí traigo, aunque de forma muy tangencial. Se trata del trabajo presentado por Mirella BlasonBerton en la Semana de Estudios Sardos celebrada en Barcelona en 1966, publicado dos años después ${ }^{6}$, donde se esboza la cuestión aunque sin incidir en ella. Y si bien en nota a pie de página la autora apuntaba su intención de analizar el tratado, hubieron de pasar unos años hasta que fuese abordado por G. Meloni en un magnífico trabajo que refería a las relaciones entre Génova y la Corona de Aragón durante los años centrales del siglo XIV ${ }^{7}$. Pese a la existencia del texto original en el Archivo de la Corona de Aragón, el mentado autor empleó una transcripción del mismo publicada en el Memorial

\footnotetext{
${ }^{3}$ Camilo MANFrONI, Il piano della campagna navale veneto-aragonese del 1351 contro Genova, "Rivista Maritima", Aug.-Sept., 1902.

${ }^{4}$ Por poner un ejemplo: Frederic C. LANE, Venice, a maritim Republic, London, 1973. John J. NoRwICH, A History of Venice, New York, 1982.

${ }^{5}$ Giuseppe Meloni, Genova e Aragona all'epoca di Pietro il Cerimonioso. I (1336-1354), Padova, 1971.

${ }^{6}$ Un'ambasciata di Pietro IV d'Aragona in Italia (1346) e i prodomi della alleanza venetoaragonese del 1351, "Anuario de Estudios Medievales", 5 (1968), pp. 237-263.

${ }^{7}$ Giuseppe Meloni, Genova e Aragona.
} 
Histórico Español ${ }^{8}$ y aunque perfectamente contextualizado en su estudio la presentación que se hace de él es limitada. Desde esa fecha hasta la actualidad se han multiplicado los trabajos referentes a las relaciones, tanto económicas como políticas, si es que acaso se pudieren diferenciar ambas, entre Italia, en lo genérico, y la Corona de Aragón, observándose a través de esos estudios la proyección de ligures, lombardos, pisanos, florentinos, sieneses, piacentinos y luqueses en el comercio mediterráneo y su fijación a los mercados catalanes, valencianos y mallorquines. Sin embargo poco es lo que conocemos respecto de Venecia. Y es que el caso de Venecia es distinto. Los intereses de la economía de la Serenissima fueron siempre orientales. El control que ejercía sobre esos mercados permitió a la república adriática no competir abiertamente con el resto de potencias, primeramente italianas y luego con la Corona de Aragón, por el espacio mediterráneo occidental. No obstante, no por ello los mercaderes venecianos despreciaron la ruta ${ }^{9}$. De ahí que la República de San Marcos no chocara nunca con los intereses de los reyes de Aragón. Es por ello también que las relaciones entre las dos potencias fuesen

${ }^{8}$ Documentos concernientes a la armada que en 1351 mandó aprestar el rey don Pedro IV de Aragón en contra de Genoveses, al cuidado de J. SANS Y BARUTELl, "Memorial Histórico Español", II, Madrid, 1851. Obra que no he podido consultar directamente.

${ }^{9}$ Sabemos que las tierras valencianas, sus fondeaderos en concreto, fueron escala obligada y prefijada de las galeras vénetas que se dirigían a Flandes, tanto a la ida como al regreso, dejando parte de la carga en los mercados locales. Asimismo, durante el Cuatrocientos naves comerciales venecianas establecieron Valencia como punto de descarga a través de dos vías, una norte que desde Sicilia avanzaba por el Tirreno, el Golfo de León y la costa catalana, y una sur, que recorría el litoral magrebí alcanzando la costa española por Málaga. Si bien, fueron las Baleares el punto de contacto más regular de las mudas vénetas. También lo fue la isla de Cerdeña, lugar en el que los venecianos se interesaron por la sal. Cf. Francisco SEVILLANO Colom, De Venecia a Flandes (via Mallorca y Portugal, siglo XIV), "Boletín de la Sociedad Arqueológica Luliana", XXXIII (1968), pp. 1-33. María Teresa FERRER I MALLOL, Els italians, pp. 461-466. Jean Claude HOCQUET, La sel et la fortune de Venise, 2 vols. Lille, 1978-1979. Giuseppe MELONI, Genova e Aragona, pp. 61-62. David IGUAL LUIS, Valencia e Italia, 389-402. Algunos documentos de cancillería nos muestran la presencia veneciana en el cuadrante occidental asaltadas por embarcaciones del rey de Aragón. Por una noticia fechada en 1333 conocemos que en pleno conflicto con Génova Alfonso IV se hace eco de un asalto en los mares sardos por parte de súbditos suyos sobre una embarcación veneciana que se dirigía a Mallorca desde aguas bizantinas con cereal, especias varias y otras mercancías. El rey de Aragón se compromete con la autoridad veneciana, un Dandolo, pariente del $d u x$ con el que se establece la alianza objeto de este trabajo, a la restitución de lo hurtado en atención a las buenas relaciones existentes entre ambas potencias. ACA, C, reg. 457, ff. 162v.-163v. Esta presencia y esta práctica ya se producía durante el reinado de Jaime II. ACA, C, reg. 182, f. 168r. Aunque también a la inversa. ACA, C, reg. 190, ff. 124v.-126v. Desde la perspectiva de la Serenissima, obsérvese tal relación en María Inés MELERO FERNÁNDEZ, Fondos medievales dell'Archivio di Stato de Venecia referentes a los reinos españoles. Regestos, "Miscel-lània de Textos Medievals" 5 (1989), regestos 1 a 5. Una reflexión de conjunto sobre la presencia italiana en Occidente en Pinuccia SiMBULA, Apertura de las rutas comerciales de las flotas italianas hacia el Atlántico, ANavegación marítima del Mediterráneo al atlántico", Antonio MALPICA (Ed.), Granada, 2001, pp. 207-258. 
contenidas. Si bien, en determinados momentos hallaron puntos de encuentro, que referían más que a un interés privativo por potenciar cualquier tipo de relación, a la focalización de un enemigo común: Génova.

Como certeramente apuntara F. Giunta "El triángulo Aragón, Venecia y Génova, en esta primera mitad del siglo XIV, centraliza todo el comercio marítimo del Mediterráneo y representa, por las ambiciones monopolistas de cada una de ellas, el estallido de una rivalidad y de una larga lucha con acontecimientos alternados" ${ }^{10}$. No deseo entrar a analizar la cuestión del expansionismo catalano-aragonés, aunque sí apuntar, en consonancia con lo expresado por el mentado autor, que el interés estratégico de este dominio fue el de consolidar su poder marítimo, también político, en el área que dibujaba la tan manida diagonal insular, para establecer una supremacía que anulase a los competidores. Primero fueron los Anjou tras la ocupación de Sicilia por Pedro el Grande -1282- y pese a la firma del tratado de Anagni trece años después el Casal de Barcelona mantuvo la vinculación con la isla tras la coronación de un hermano de Jaime II como rey de Sicilia. Luego vendría Génova.

Todos los autores son coincidentes a la hora de señalar la conquista de Sicilia como el punto de inflexión en las relaciones entre Génova y la Corona de Aragón ${ }^{11}$. Hasta esa fecha la "expansión mediterránea" catalana alcanzaba en clave política al reino insular de las Baleares, mientras que su proyección comercial no era competencia para los ligures. Pero la adquisición por parte de Jaime II de la isla de Cerdeña en 1324, como resultado de la aplicación de los acuerdos de Anagni, explicitaron los peligros visualizados por los genoveses de que esa presencia iba más allá de la competencia comercial. Es, además, una época, la última década del Doscientos y la primera del Trescientos, de conflictividad y cambios, como la ha denominado A. Riera, en todo el Mediterráneo; Venecia y Génova, por poner un ejemplo, conocen de tensiones políticas internas al tiempo que quedan obligadas a

\footnotetext{
${ }^{10}$ Francesco GiUNTA, Aragoneses y catalanes en el Mediterráneo, Barcelona, 1989, p. 146.

${ }^{11}$ Cf. Giuseppe Meloni, Genova e Aragona, pp. 3-20. Geo PISTARINo, Genova e Barcellona: incontro e scontro di due civiltà, "Atti del I Congresso Storico Liguria-Catalonia", Bordighera, 1974, pp. 81-122. María Teresa FerRer I MALLol, Els italians, p. 435. G. JeHEL, Angevins, génois et siciliens aux temps des Vêspres (1276-1337), "XI Congresso di Storia della Corona d'Aragona", vol. III (1984), pp. 257-277. Roser SALICRÚ I LLUCH, Noticies de genovesos al regne de Múrcia al tombant del segle XIII, "Anales de la Universidad de Alicante. Historia Medieval", 11 (1996-1997) Actas del Congreso Internacional Jaime II Setecientos años después, pp. $482-483$.
} 
reestructurar sus líneas comerciales como consecuencia de la toma de Acre en 1291 por los mamelucos y el veto papal al comercio con musulmanes ${ }^{12}$.

El dominio sardo de la Corona de Aragón perjudicaba de manera notable al comercio genovés, muy asentado en Sásser. "La posición estratégica de la isla - dice J. Mutgé- que hacía que quien la dominara estuviera en condiciones de vigilar sus propias naves y amenazar las rivales, explica que el mismo empeño que Jaime II y sus sucesores pusieron en conservar Cerdeña, lo pusiera Génova en arrebatársela, pues era para ella la garantía de su prosperidad económica"13. Y su reacción no se hizo esperar, abriendo abiertamente la guerra contra la Corona de Aragón. Esta primera guerra duró todo el reinado de Alfonso IV, y aunque no se produjera ninguna gran batalla naval, quedando reducida a escaramuzas y captura de naves por ambas partes, los ligures demostraron la potencia de su marina al bloquear Sicilia y amenazar las costas catalanas y levantinas, pero fundamentalmente la facilidad que tenían para armar una gran flota con la que poner en jaque los intereses del rey de Aragón ${ }^{14}$. Sería necesaria la intervención de dos papas, Juan XXII y Benedicto XII, para que se alcanzase la tan anhelada paz, y aunque fue Alfonso IV quien más la deseaba la muerte le sorprendió antes de su firma, habiendo de ser su sucesor, Pedro, quien la signase en el verano de $1336^{15}$.

Esta primera guerra no hizo sino poner sobre la mesa el debate acerca de la supremacía en el Mediterráneo Occidental. Y la firma de la paz no era sino un punto y aparte en la carrera por ese dominio. Cualquier acción, por precaria que fuere, llevaría a las armadas al agua. Y ocasiones no faltaron ${ }^{16}$. En Cerdeña, los ligures contaban con grupos rebeldes al dominio aragonés encabezados por la familia Doria. Pero Génova tampoco carecía de enemigos.

${ }^{12}$ Antoni RIERA I MELIS, El context mediterrani de la primera fase del regnat de Jaume II (1291-1311): conflictivitat i canvis, en "Anales de la Universidad de Alicante. Historia Medieval", 12 (1999), pp. 183-205.

${ }^{13}$ Josefina MUTGÉ VIVES, El Consell de Barcelona en la guerra catalanogenovesa, durante el reinado de Alfonso el Benigno (1327-1336), "Política, urbanismo y vida ciudadana en la Barcelona del siglo XIV", Barcelona, 2004, pp. 50-52 y ss. Publicado en origen en "Anuario de Estudios Medievales", 2 (1965), pp. 229-256.

${ }^{14}$ Ibídem.

${ }^{15}$ Acerca de esta paz cfr. ACA, C, reg. 556, ff. 14v.-18r.

${ }^{16}$ Un reflejo de la situación en los primeros años de gobierno de Pedro el Ceremonioso en Giuseppe MELONI, Genova e Aragona, pp. 23-34. 
Su apertura a aguas del Levante mediterráneo le enfrentó con Venecia ${ }^{17}$. Es así que Pedro IV, que hasta la fecha había mantenido una relación de absoluta distancia diplomática respecto de la Serenissima, como habían hecho sus antecesores, encontrase un aliado coyuntural con el que compartir gastos y beneficios en su empresa contra Génova. La relación, en teoría, había de ser provechosa para ambas potencias, pues ambas tenían establecidas sus prelaciones en el terreno comercial. Es así que por más que la Corona de Aragón abriese una fecunda proyección en los mercados mamelucos de Siria y Egipto ${ }^{18}$, era el espacio mediterráneo occidental el que sobresalía en la tabla de resultados económicos. Y viceversa respecto de Venecia.

En esos años centrales de la década de 1340, Pedro el Ceremonioso conoció de graves problemas internos, desarrollándose un conflicto doméstico en los reinos de Aragón y Valencia, la Unión, que ponía en jaque a la propia monarquía ${ }^{19}$. La Unión era una respuesta de aragoneses y valencianos al autoritarismo regio, los primeros en la exigencia del reforzamiento de los derechos feudales y los segundos en la solicitud de garantías legales que evitaran las continuas violaciones de los privilegios del reino ${ }^{20}$. El asunto, larvado de tiempo atrás ${ }^{21}$, se activó cuando Pedro IV quiso modificar el secular modelo de transmisión masculina al trono para favorecer a su hija Constanza, al no haber engendrado varón y en contra de los derechos aducidos por su hermano Jaime, conde de Urgell ${ }^{22}$. A ello se unía la activación del problema sardo por pisanos y genoveses. Preocupado por la cuestión interna, a finales de 1346 envió a un embajador a tierras italianas para tratar de

${ }^{17} \mathrm{Al}$ respecto de las guerras anteriores entre ambas potencias cf. Frederic C. LANE, Venice, John J. NORWICH, A History, .

${ }^{18} \mathrm{Cf}$. Damien Coulon, Barcelone et le commerce d'Orient au Moyen Âge. Un siècle de relations avec l'Égypte et la Syrie-Palestine (ca. 1330-ca. 1430), Madrid-Barcelona, 2004.

${ }^{19}$ Mateo Rodrigo Lizondo, La Unión valenciana y sus protagonistas, "Ligarzas", 7 (1975), pp. 133-166. Esteban SARASA SÁNCHEZ, El enfrentamiento de Pedro el Ceremonioso con la aristocracia aragonesa: la guerra contra la Unión y sus consecuencias, "Pere el Cerimoniós i la seva època", Barcelona, 1989, pp. 35-45.

${ }^{20}$ En el caso valenciano habría que recordar el intento de Alfonso IV años atrás de ampliar el señorío de su hijo Fernando sobre importantes dominios realengos, que venían a dejar buena parte del reino en manos del infante.

${ }^{21}$ Cf. Luis GonZÁLEZ ANTÓN, Las uniones aragonesas y las Cortes del reino (1283-1302), 2 vols. Zaragoza, 1975. Carlos LALIENA CORBERA, La adhesión de las ciudades a la Unión. poder real y conflictividad social en Aragón a fines del siglo XIII, "Aragón en la Edad Media. Homenaje al Profesor Emérito Antonio Ubieto Arteta", VIII (1989), pp. 399-413.

${ }^{22}$ Jerónimo ZURITA, Anales de Aragón, Zaragoza, 1978, 4, VIII, V. 
alcanzar una paz con Génova que neutralizase la cuestión sarda. Si bien, en paralelo ese legado había de pulsar la creación de una liga antigenovesa con diversas señorías italianas como Milán, Florencia, Verona, la propia Venecia, Pisa, Ferrara, Padua, Mantua y Bolonia ${ }^{23}$. Parece evidente, a la luz de la solicitud del rey Ceremonioso a su embajador, que desde la Corona de Aragón se tenía poca confianza en alcanzar un acuerdo con los ligures ${ }^{24}$. Los interlocutores italianos era los Visconti milaneses, con quienes la Corona de Aragón había establecido una relación diplomática ciertamente buena que ahora Pedro IV quería impulsar ${ }^{25}$. En el posible acuerdo antigenovés se proponía la colaboración bilateral con cierto número de caballeros y de galeras, sin especificar, cuya financiación correría a cargo de quien solicitase el apoyo ${ }^{26}$.

Mientras Pedro IV ahogaba las pretensiones políticas de los rebeldes unionistas aragoneses y valencianos en las batallas de Épila y Mislata, en Italia los conflictos entre las señorías también se hicieron notar. La guerra entre Milán y Génova obligó a ligures y a sus aliados pisanos a mandar sendas embajadas a Pedro IV para comunicarle, tras unos preliminares reproches acerca de cómo fueron despojados de sus posesiones sardas, que por ello no iniciarían un conflicto contra el rey de Aragón. La respuesta de Pedro IV, sujeta al más estricto orden jurídico, a la más absoluta legalidad internacional - la infeudación recibida por su abuelo de Córcega y Cerdeña de manos de la Iglesia-, deslegitimaba cualquier intento genovés por alterar la situación si no se hacía por idéntica vía ${ }^{27}$. Lo cierto es que Génova no estaba dispuesta a perder el control sobre los mares sardos, que hacían de la isla no sólo escala necesaria para sus naves sino imagen subjetiva de su supremacía marinera en el Occidente Mediterráneo, ahora seriamente cuestionada por la Corona de Aragón ${ }^{28}$.

\footnotetext{
${ }^{23}$ Mirella Blason-Berton, Un'ambasciata di Pietro IV, p. 239 y docs. n.1 3 y 4.

${ }^{24}$ Como así se demostraría, pues en el verano de 1347 los Doria, aliados sardos de Génova, vencieron militarmente a las tropas del gobernador de Cerdeña por el rey de Aragón. La situación en la isla era claramente de guerra abierta. Jerónimo ZURITA, Anales, 4, VIII, XVI.

${ }^{25} \mathrm{G}$. SORGIA, I Visconti di Milano, l'Aragona e la Sardegna nel secolo XIV atraverso la lettura dello Zurita, "VIII Congreso de Historia de la Corona de Aragón", Barcelona, 1962, II, pp. 393-396.

${ }^{26}$ Mirella Blason-Berton, Un'ambasciata di Pietro IV, pp. 245-246 y doc. n.1 4.

${ }^{27}$ Jerónimo ZURITA, Anales, 4, VIII, XXVIII, pp. 134-136.

${ }^{28}$ Ibídem, p. 136. La situación político-militar de la isla antes de la firma del tratado con Venecia cfr. en Giuseppe MELONI, Genova e Aragona, pp. 35-54.
} 
Desde una supuesta paz con Aragón, la república ligur apoyaba a los rebeldes sardos. Hasta tal punto fue así que éstos ofrecieron el dominio de Alguer a Génova, que lo aceptó enviando hasta allí a un gobernador de la nueva señoría. A los protestas de Pedro IV ante una injerencia tal dentro de sus dominios, el Común propuso la negociación en la Corte papal de una nueva paz. Hablamos claramente de un conflicto civil sardo inserto en otro de carácter internacional por la hegemonía política y comercial del Mediterráneo occidental. Este es el momento elegido por Venecia para entrar en el juego. Con el apoyo a Aragón, sin que éste haya de entenderse necesariamente como epílogo de la embajada de $1346^{29}$, que no dudo hiciese papel de reclamo, la Serenissima ensanchaba la guerra a todo el Mare Nostrum, dirigiendo a Génova hacia un bifrontismo naval Levante/Poniente que le obligaba a multiplicar los costes militares para proteger sus naves y rutas de la presión de catalanes y venecianos.

\section{LAS NEGOCIACIONES Y EL PACTO}

La primera noticia que tenemos acerca de esta relación diplomática fuera del estricto marco documental es la ofrecida por J. de Zurita, quien señala la presencia en la Corte de un nuncio veneciano, Giovanni Gradenigo, que en nombre de aquella señoría insistió que el rey se confederase con ella contra los genoveses, cosa que consiguió con grande instancia muchos días que estuvo sobre ello en la villa de Perpiñán ${ }^{30}$. Previa a esas noticias, la Crònica de Pedro el Ceremonioso en su capítulo V, dedicado a explicar los entresijos de la confederació e avinença ab lo duc e comú de Venècia contra lo duc e comú de Gènova, e tots los afers qui es seguiren aprés la dita confederació $^{31}$, refiere esos acontecimientos tomados por el cronista aragonés. El propio rey nos cuenta que entre los miembros del consejo real había opiniones divididas, unos que apoyaban la opción veneciana, recordando al rey todos los agravios cometidos por los ligures a él y a sus súbditos, y otros, más timoratos, que pedían una aproximación a ese enemigo dient que més

\footnotetext{
${ }^{29}$ Giuseppe Meloni, Genova e Aragona, p. 35.

${ }^{30}$ Jerónimo ZURITA, Anales, 4, VIII, XLV, p. 204.

${ }^{31}$ Crònica de Pere el Cerimoniós, en Les Quatre Grands Cròniques. Revisió del text i notes per Ferran SoLDEVILA, Barcelona, 1971, p. 1111 y ss.
} 
valia confermar la pau per tal com ells eren hòmens fort destres en la mar e que en poguéren haver damnatge, por razón de la cercanía entre esa república y los dominios sardos del Ceremonioso ${ }^{32}$. Que una vez oídas las opiniones se inclinó por Venecia, firmando un acuerdo en el que se establecía el pago de una cierta cantidad de dinero a la Corona de Aragón por el armado de una flota que había de partir hacia aguas del Egeo a combatir a los genoveses ${ }^{33}$. Y que en agosto de 1351, tras un cruce dialéctico entre Pedro IV y un embajador genovés llamado Cristoforo Paolo producido en el mes de abril, mandó carta de desafío al duque y común de Génova con los porteros reales y a todos sus súbditos como a quebrantadores de la fe y paz y públicos enemigos $^{34}$.

Nada que objetar a la muy documentada visión de Jerónimo de Zurita al respecto de lo que refiere, en líneas generales. Sin embargo, es conveniente puntualizar ciertos datos. Algunos de extremo rigor en el detalle, como el nombre del embajador veneciano artífice del acuerdo, que no fue Giovanni Gradenigo $^{35}$, aunque también ejerciera tal función, como posteriormente veremos, sino Giovanni Steno. Otros algo más relevantes, como que el acuerdo con la Serenissima se había cerrado en las Navidades de 1350; el deseo de derrotar militarmente al enemigo ligur era muy anterior.

En el verano de 1350 la tensión en el Egeo entre venecianos y genoveses había desembocado en una nueva guerra ${ }^{36}$. Una vez rotas las hostilidades la República de San Marcos decidió captar aliados en esa lucha y, conocedora de las dificultades políticas que su enemigo tenía con la Corona de Aragón, puso en marcha su maquinaria diplomática para activar una negociación con Pedro el Ceremonioso enviando un embajador a Perpignan,

${ }^{32}$ Ibídem, p. 1112. J. ZURITA, Anales, 4, VIII, XLV, pp. 204-205.

${ }^{33}$ "E la dita covinença fo feta e fermada en aital manera que el dit comú de Venècia donàs $\mathrm{e}$ pagàs a nós certa quantitat de moneda per cascuna de les galees nostres, per pagar lo sou de la xurma e de la panàtica e altres aventatges; així emperò que l'armada nostra primerament feedora, degués anar a les parts de Romania e mesclar-se ab les armades del comú de Venècia e fer la guerra contra genoveses així com acordarien los capitans del senyor rey e del dit comú". Crònica de Pere el Cerimoniós, p. 1112.

${ }^{34}$ Jerónimo ZURITA, Anales, 4, VIII, XLV, p. 207.

${ }^{35} \mathrm{R}$. Tasis en su biografía de Pedro el Ceremonioso también señala a Gradenigo como el embajador veneciano impulsor de los acuerdos con la Corona de Aragón, quizá tomando el nombre de Zurita. Rafael TASIS I MARCA, La vida del rei En Pere III, $2^{\mathrm{a}}$ edició, Barcelona, 1961, p. 140.

${ }^{36}$ Giuseppe Meloni, Genova e Aragona, pp. 58-60. Frederic C. LANE, Venice, pp. 175-176. John J. NORWICH, A History, 1982, p. 216. 
donde se encontraba el rey. El designado fue Giovanni Steno ${ }^{37}$, a quien el 10 de septiembre se le expedía carta credencial como legado de la República firmada por el $d u x$ en el palacio ducal y actuando de testigos Benitendi, vicecanciller del ducado, así como varios prohombres, caso de Vitale de Fuschis, Stefano Ziera o Bartolomeo Ursio, notarios venecianos. En ese documento se expresaba que Andrea Dandolo ${ }^{38}, d u x$ de Venecia, Dalmacia y Croacia y domini quarte partis et dimidie tocius Imperii Romanie, rodeado de sus consejeros y todos a una voz, nemine discrepante, designaron como síndico y procurador al nobilem et sapientem virum dominum Giovanni Steno para comparecer ante Pedro IV y firmar una alianza, tratado, liga o unión tanto contra el Común de Génova, sus cómplices y colaboradores, como contra los bienes, navíos, ciudades, cosas, tierras y lugares de éstos o contra cualesquiera otras personas calificadas de enemigos de ambos regímenes. Con ese fin se obligaba el firmante con todos los bienes del Común veneciano, lo que, sin duda, era un brindis al sol, pero reflejaba la voluntad manifiesta de alcanzar tal acuerdo. El procurador nombrado por la señoría, Steno, tenía poderes plenipotenciarios para pactar aquello que considerase, obligándose $d u x$ y Común a observar en su integridad el resultado de lo pactado, sin posibilidad de modificación, bajo la obligación de todos los bienes de la República.

Presentadas sus credenciales al rey de Aragón, éste aceptó el inicio de las negociaciones designando como delegado suyo para tal fin a Bernat de Cabrera, uno de lo hombres fuertes del reino, posiblemente el principal consejero de Pedro IV y dese luego el más firme valedor de la alianza con la Serenissima. Ambos personajes abrieron el juego diplomático entre Venecia y la Corona de Aragón quizá a principios del otoño, aunque en fecha indeterminada. El resultado de las conversaciones, que no debieron ser fáciles, tomó forma de documento a la vuelta de Navidad, ya 1351, firmado en el castillo regio de la ciudad de Pepignan el 16 de enero, donde se establecía una alianza militar entre la Corona de Aragón y el Común

\footnotetext{
${ }^{37}$ Giovanni Steno era miembro de una de las familias patricias más importantes, que junto a otras como Bembo, Cocco, Dandolo, Giustinian, Gradenigo o Pisani, alguno de cuyos miembros aparece vinculado a los sucesos que aquí se analizan, dominan la escena política veneciana en el Trescientos. Stanley CHOJNACHI, In Search of the Venetian Patriciate: Families and Factions in the Fourteenth Century, en J.R. HALE (ed.) Reinassance Venice, London, 1973, pp. 47-90.

${ }^{38}$ Acerca de este personaje cf. Carlos DIEHL, Una república de patricios: Venecia, Madrid, 1961, pp. 129-130. Frederic C. LANE, Venice, pp. 179-180. John J. NoRWICH, A History, pp. 214-229.
} 
veneciano contra la República de Génova. Fueron testigos de ello Bernat de Cabrera y Mateu Mercer, mayordomo de Pedro IV, ambos caballeros y consejeros regios, así como Rafaino de Caresini y Nicola de Lambertis, notarios del ducado de Venecia, junto al propio embajador Steno.

La alianza militar que se establecía sin duda era muy provechosa para ambas potencias. El freno a la acción comercial genovesa en el Mediterráneo equivalía al reforzamiento de esa misma actividad para los firmantes, que implícitamente, como veremos en el análisis de los capítulos de la liga, se repartían las dos grandes áreas mercantiles del antiguo Mare Nostrum, oriente y occidente, sobre el eje siciliano. Para la Corona de Aragón el comercio representaba ya a esas alturas el principal motor de la economía, desde luego en las áreas litorales -Cataluña, Valencia, Mallorca-. Es por tal que Pedro IV no pudiese dudar en apuntalar uno de los pilares de la prosperidad de sus reinos en un momento, además, de dificultades en todos los órdenes. Habría que recordar que junto a las divergencias políticas entre rey y reino/os, desde unas cuantas décadas atrás se observaba en todos los territorios de la península ibérica un conjunto de signos denunciadores de una situación general de desestabilización económica - crisis de producción, focalizada fundamentalmente en lo mal any primer de 1331, que provocaron hambrunas, caída de las rentas señoriales, cierto descenso demográfico, etc.-, de la que sólo se libraba el comercio. Todavía no se habían valorado por los contemporáneos los efectos devastadores de la peste negra que por entonces arrasaba toda Europa, aunque se conociese de las innumerables bajas que estaba causando.

Para la Serenissima el acuerdo con la Corona de Aragón representaba otro tanto de lo mismo. La fuerte presencia ligur en las rutas y mercados del Levante desde fines del Doscientos venía mermando la potencialidad veneciana $^{39}$. Es por ello que $d u x$ y Común, en un período de clara recesión en la coyuntura económica para la República ${ }^{40}$ y de profundo hundimiento demográfico como consecuencia de la corriente pestífera, apostasen por una alianza militar que en buena medida sufragaban económicamente, quizá

${ }^{39}$ Choque de intereses desde dos modelos económicos claramente disimétricos: un proyecto colonial diseñado y controlado por el estado, en el caso de Venecia, frente al más dinámico y personalista ligur, desarrollado por la iniciativa privada. Mario GALLINA, Gli italiani nell Mediterraneo, en Pietro CORRAO, Mario GALLINA, Claudia VILlA, L'Italia mediterranea e gli encontri di civiltà, Roma-Bari, 2001, p. 201. 126.

${ }^{40}$ Gino LuZZATO, Storia economica di Venezia dall'XI al XVI secolo, Venezia, 1995, pp. 123- 
porque la necesitaban más que la Corona de $\operatorname{Aragón}^{41}$. F. C. Lane refiere también que a estos problemas se unía el escaso ardor guerrero del veneciano de mediados del Trescientos, que con un alto poder adquisitivo prefería pagar a sustitutos que participar en las operaciones militares de la señoría ${ }^{42}$. Es así que este mismo autor asevere que la confianza de los venecianos en su riqueza era claramente proporcional a la desconfianza que mostraban en sus recursos humanos. La solución pasaba por la contratación de milicias extranjeras, bien en calidad de mercenarios o bien, como en el caso de aquí se apunta, a través de la vía diplomática ${ }^{43}$.

Las razones expuestas por ambas partes en el preámbulo del acuerdo de colaboración, dentro del marco de una justificación claramente parcial de la realidad política, respondían a la iniquidad de los genoveses, quienes sin temor de Dios se daban a la rapiña en los mares, prodigándose en acciones piráticas que producían graves et intollerabiles iniuriuas et offensas ac damna, tanto en tiempos pasados como en los presentes a los súbditos del rey de Aragón como a los del $d u x$ y Común de Venecia. Con el ánimo de acabar con tales abusos, y a la espera de la ayuda divina para alcanzar tal fin, ambas potencias habían cerrado un pacto sobre la base de unos capítulos. Son los que siguen.

1. El establecimiento de una liga, acuerdo o unión entre los firmantes contra Génova desde ese mismo día hasta la festividad de San Miguel Arcángel -29 de septiembre- y de ahí durante los cuatro años siguientes. Medio año antes de la finalización de la entente, las partes podrían estimar o desestimar su prórroga.

\footnotetext{
${ }^{41}$ "Esistevano, quindi, i presupposti per un'alleanza, anche se alle sue basi non stava una chiara comunità di interessi, ma l'esigenza di far fronte comune contro il nemico. Aggiungeremo che chi rimprometteva di ricavare i maggiori vantaggi dall'alleanza era Venezia, gravemente minacciata nei suoi forti interesse commerciali dallo scontro aperto in Oriente con le posizioni genovesi, piuttosto che non l'Aragona, la quale intravvedeva ancora possibile una soluzione di compromesso". Giuseppe MelonI, Genova e Aragona, p. 62.

${ }^{42} \mathrm{El}$ citado autor apunta de las dificultades de las autoridades venecianas para reclutar tripulaciones destinadas a su flota tras la pandemia de 1348, habiendo de emplear base humana de otros territorios, como Dalmacia y las colonias griegas. Aún así, y con el sistema tradicional de reclutamiento de galeras, en 1350 se pudo disponer de la mitad de las embarcaciones que se armaron en 1294. Frederic C. LANE, Venice, p. 175.

${ }^{43}$ Idéntica propuesta que se cursa al rey de Aragón se hará al emperador bizantino cara a la obtención de una gran armada para recuperar la hegemonía en el Egeo. Ibídem, pp. 176-177. A este respecto, $R$. Tasis es de la opinión que la inclusión en la liga antigenovesa del bizantino Juan Cantacuceno se decidió por la intervención del rey de Aragón. Rafael TASIS I MARCA, La vida, p. 141.
} 
2. Durante el tiempo de duración de los acuerdos ninguna de las partes firmantes, de modo unilateral, podría hacer paz o tregua con el $d u x \mathrm{y}$ Común genovés sin el expreso consentimiento y voluntad del coaligado.

3 . En la guerra que ahora daba comienzo entre genoveses y venecianos, el rey de Aragón debía tener prestas anualmente durante el tiempo establecido en el acuerdo de colaboración dieciocho galeras - tam in estare quam in ytinere - dispuestas para la acción in ripparia Janue, es decir in regno Sicilie versus rippariam Janue, o lo que es lo mismo el Mar Tirreno. Tal número de embarcaciones había de hacer guerra a los genoveses en esas aguas proporcionándoles todo el daño que pudiesen.

4. Las dieciocho galeras pactadas habían de ser armadas por el rey de Aragón, quien además se debía ocupar del reclutamiento de la tropa, y de ellas dos terceras partes serían sufragadas por los venecianos, quedando las restantes a cargo de la Corona de Aragón. Pedro IV había de velar por que las dieciocho galeras estuviesen perfectamente armadas durante el tiempo explicitado en el acuerdo, mientras que Venecia se comprometía a satisfacer por el mantenimiento de las doce naves que quedaban a su cargo doce mil florines florentinos de oro mensuales, es decir mil florines por galera y mes. Esos pagos tendrían inicio el mismo día en que las embarcaciones quedasen armadas en el puerto o playa donde se hubiese realizado su construcción, mejora y armado, y se suspendería el día en que acudiesen a puerto para ser desarmadas. Los pagos, por parte veneciana, relativos a la parte de la flota que quedaba a su coste se realizarían en la ciudad de Avignon, la corte papal, del modo que el rey de Aragón considerase oportuno. Asimismo, los venecianos estimaron que el almirante de la flota sería quien Pedro IV designase. El $d u x$ Dandolo dispuso que el primer pago se haría en Avignon por los primeros cuatro meses, quedando cubierta la cantidad establecida para el mantenimiento de la flota en la parte que correspondía a Venecia hasta mediados de marzo del año siguiente, y así sucesivamente de manera cuatrimestral.

5. El lucro o botín de guerra obtenido de la acción de esas dieciocho galeras quedaría dividido en tres partes, una para el almirante y las dos restantes para cada firmante, Aragón y Venecia.

6. Dos nobles venecianos expertos en la guerra naval así como en el arte de la marinería, designados por el $d u x$ y Común, habían de quedar junto al almirante de la armada. No obstante la presencia de estos marinos de la Serenissima, toda la jurisdicción y gobierno de la flota correspondería al capitán nombrado por el rey de Aragón. 
7. Las vituallas y los salarios de los integrantes de la flota quedaban bajo la responsabilidad de Pedro IV.

8. En el supuesto de que una flota genovesa de diez o más galeras saliese de Génova vel Rippuaria y casualmente no fuese avistada por la armada véneto-aragonesa, de tal modo quod transirent bucham de faro para dirigirse a otra parte - es curioso que se obvie la longitud-, el almirante o capitán de la citada armada habría de proceder de modo inmediato a localizar y perseguir la escuadra genovesa ${ }^{44}$.

9. En caso de que se acordase por ambas partes incrementar el número de galeras respecto de las dieciocho comprendidas en este acuerdo, el rey de Aragón sería el responsable de dotarlas humanamente con sus gentes, bajo la forma antes expresada, es decir los venecianos habrían de pagar mensualmente en Avignon mil florines por cada una de las galeras a razón de dos partes sobre las nuevas naves armadas. Con esas embarcaciones se haría guerra continua contra Génova en los lugares y espacios establecidos en el acuerdo, y el lucro obtenido, el botín de guerra, se dividiría igualmente del modo predicho respecto de las dieciocho galeras establecidas en el acuerdo inicial. Esas nuevas embarcaciones armadas debían quedar en servicio por el tiempo que las partes conviniesen. En el caso de que el Común de Venecia desease armar galeras con sus gentes, además de las dieciocho establecidas, podría hacerlo en los dos tercios que habían de financiar. De producirse esto, las naves venecianas quedarían igualmente bajo la jurisdicción y gobierno del almirante de la flota, nombrado como sabemos por el rey de Aragón.

10. Tanto desde la Corona de Aragón como desde la República de Venecia se había de declarar a Génova como público enemigo, no comerciando, conversando o manteniendo trato alguno con esa potencia, así como practicándole todo el daño que pudiesen.

11. El acuerdo firmado entre las partes quedaría vigente por todo el tiempo establecido. Se apuntó que si el rey de Aragón, antes del cumplimiento del período marcado por ambas partes en la alianza militar, decidiese firmar tregua o paz con el enemigo, las mentadas galeras debían servir y continuar la guerra en el modo previsto hasta la finalización del tiempo estipulado en el acuerdo, en atención, básicamente, al pago realizado por los venecianos. En caso contrario, el rey de Aragón habría de restituir al Común de Venecia el

\footnotetext{
44 "Si sicut dicto ammirato et viceammirato dicti domini regis et predictis nobilibus de Venecie, vel maiori parti eorum, videbitur id ad honorem et bonum partium ac confusionem hostium redundare".
} 
desembolso realizado. Este punto, incluido por petición expresa del embajador de la Serenissima, Pedro IV prometió respetarlo solemnemente.

12. Si una vez firmada la paz Génova decidiese iniciar de nuevo otra guerra contra Venecia durante tempore supradicto, en clara alusión al marco temporal establecido entre la firma de la tregua y la conclusión del acuerdo de colaboración entre Pedro IV y el $d u x$ Dandolo, por la razón que fuera, la Corona de Aragón habría de unirse al Común veneciano contra los ligures según la forma pactada anteriormente, es decir la tercera parte de la armada la pagaría el rey aragonés y los dos tercios restantes la Serenissima.

13. Asimismo, de ocurrir esto, el lucro obtenido por la acción de la armada quedaría igualmente dividido del modo predicho.

El armado y aprovisionamiento de las galeras se había de realizar en las marítimas del rey de Aragón tal y como quedó establecido anteriormente. Para ese fin, el rey Pedro había de observar una serie de directrices establecidas en el acuerdo. Cada galera navegaría con: unus generosus vel civis reputacionis generis et status honorifici cum se tercio sociorum, un comitus, un subcomitus, ocho pilotos de nave, treinta ballesteros, ciento ochenta remeros, dos palomerii, un escribano seu senescallus y un tubicelle o tubicinator, es decir trompeta o trompetero. En cuanto al armamento de cada embarcación, con excepción de las jarcias y otras cosas necesarias para las naves, el generoso o ciudadano y sus dos socios habían de poner en su nave sui corporis arme complete, mientras que el comitus, el subcomitus, los pilotos, los ballesteros, los proherii, los alierii, los espatlerii y los cruillerii de igual modo portarían sus propias armas. Los ballesteros, además, habían de llevar dos buenas ballestas y doscientos viratones. Los proherii y alierii junto a dichas armas singulos pavesios. La armería de cada galera debía contar además con cien gorgueras, cien cascos de hierro, cien paveses, cien viratones, seis mil lanzas, quinientos dardos, mil picas y otras materias.

Además de todo esto, el rey de Aragón se comprometía con el embajador veneciano Steno a que una vez recibido el pago de las doce galeras en Avignon, y en el término pactado, las dieciocho naves que componían la flota de la coalición quedarían perfectamente armadas en los puertos y playas del rey de Aragón para hacer guerra vivaciter et efficaciter contra Génova durante todo el mes de mayo y de ahí en adelante. Fue igualmente establecido por ambas partes que de estimarse la conveniencia de disminuir el número de galeras de la armada se hiciese, sin que ello significase merma en la eficacia de las acciones contra el enemigo. El reparto del botín, de decrecer el número de barcos, sería proporcional al modelo establecido. 
Las potencias ajustaron respetar escrupulosamente el contenido de todos y cada uno de los capítulos establecidos en la alianza militar y no contravenirla en ninguno de sus puntos bajo pena de cien mil florines de oro por cada capítulo quebrantado. Todas las posesiones de los firmantes quedaban ligadas por este acuerdo, no pudiendo ninguna de ellas aducir que se la exceptuase de la general obligación que marcaba esta liga antigenovesa. Juraron asimismo ante los Evangelios Pedro IV, de un parte, y Giovanni Steno, en cuanto procurador de la señoría y Común de Venecia, de otra, llevar a efecto todo lo escrito y observarlo íntegramente. El embajador veneciano se comprometía a que a su regreso a la ciudad de los canales, el $d u x$, en presencia de sus nobles y consejeros, haría similar juramento ante los embajadores que Pedro IV enviaría a tal efecto, con reflejo por escrito, en un plazo no superior a diez días después de que Giovanni Steno llegase a Venecia e informase a su señor del resultado de las negociaciones con el rey de Aragón.

Cerrados todos los flecos del acuerdo, se dispuso que fuesen redactados dos documentos exactamente iguales donde se recogiesen los términos de la alianza entre la Corona de Aragón y la República de Venecia; uno quedaría en poder del rey de Aragón y el otro pasaría a manos del embajador italiano que habría de portar al $d u x$ y Común de Venecia ${ }^{45}$.

Se trataba, pues, de un acuerdo militar bastante al uso, ciertamente similar, por otro lado, al establecido veinte años atrás por Barcelona y Mallorca en sus luchas contra Génova, en el que destaca, dentro del estándar, el establecimiento de un tiempo amplio, cuatro años, aunque a lo que parece Pedro IV aspiraba en origen a que la alianza alcanzase una década ${ }^{46}$, y luego fórmulas ya clásicas como la fijación de los criterios concernientes a la financiación de la flota, el reparto del botín o la inconveniencia, casi nunca cumplida, de la firma de paces unilaterales con el enemigo. Destaca frente a la alianza de 1330 una novedad, y es que se trata de una empresa de la monarquía frente a aquélla en que eran las ciudades quienes procedían a la

\footnotetext{
${ }^{45}$ ACA, C, reg. 556, ff. 49r-51v. María Inés MELERo FernándEZ, Fondos medievales ..., regesto 5, donde refiere a la localización de la copia veneciana de la alianza en el Archivio di Stato de la ciudad de los canales. Una visión resumida del acuerdo en Giuseppe MELONI, Genova e Aragona, pp. 65-66.

${ }^{46}$ Giuseppe Meloni, Genova e Aragona, p. 65.
} 
organización de una armada contra los ligures, en la que cabía la iniciativa privada, enfocada más como negocio que como acción de ardor patrio ${ }^{47}$.

Imaginamos que se trataría de una negociación secreta. Si bien la Corte regia de Perpignan era por entonces un hervidero de agentes en misión diplomática, alguno de ellos genovés, que conoció rápidamente de esa avenencia y comunicó con igual celeridad a Génova. La respuesta evasiva de Pedro IV el 19 de abril de 1351 a la encendida petición de un embajador ligur de clarificar la relación entre ambas potencias, además de dejar patente las intenciones del Ceremonioso, explican el conocimiento que los genoveses tenían de esos acuerdos desde poco después de su establecimiento ${ }^{48}$.

\section{LA ACTIVACIÓN DE LA ALIANZA. FLECOS DIPLOMÁTICOS Y NUEVAS EMBAJADAS}

Teniendo presente una de las cláusulas del pacto firmado entre la Corona de Aragón y la Serenissima para establecer una alianza militar en la guerra contra Génova, Pedro el Ceremonioso dispuso que junto al embajador Steno viajase hasta Venecia una delegación aragonesa para recibir del $d u x$ Dandolo la ratificación escrita de los acuerdos adoptados en un plazo no superior a diez días después de que su nuncio en Perpignan le hubiese informado acerca de la liga establecida. Para tal asunto nominó a dos personas de su entera confianza, Azbert de Gatell, de la casa del rey, y Bertran de Pinós, escribano regio, en calidad de procuradores plenipotenciarios, certos et speciales, para realizar tal misión. De suceder así, Pedro IV ratificaría todo aquello que sus embajadores realizasen, eximiéndoles en persona y bienes de cualquier acción que se pudiese llevar a cabo en su contra. Este nombramiento se efectuó en el aula regia mayor del palacio real de Barcelona el 28 de mayo de $1351^{49}$.Unos días después, el 1 de junio, era firmada y sellada por el rey copia auténtica, realizada por el escribano regio Mateu Adrià, del texto de la liga militar establecida con el Común de Venecia contra la república ligur, que con toda seguridad habían de portar los legados aragoneses a la corte ducal ${ }^{50}$.

\footnotetext{
${ }^{47}$ Josefina Mutgé VIVES, El "Consell" de Barcelona, pp. 54-55.

${ }^{48}$ Jerónimo ZURITA, Anales, 4, VIII, XLV.

${ }^{49} \mathrm{ACA}, \mathrm{C}$, reg. 556, f. 55r.-v.

${ }^{50} \mathrm{ACA}, \mathrm{C}$, reg. 556, f. 56r.
} 
Aunque formalmente la activación de la entente requería de la confirmación veneciana del modo descrito en el pacto, desde mediados de marzo las naves que se habían de emplear contra Génova se armaban en los puertos de la Corona de Aragón en atención a que la Serenissima realizó el primer pago en esas mismas fechas ${ }^{51}$.

El 4 de junio Pedro IV comunicaba a todos y cada uno de los prelados, barones, caballeros et aliis amicis devotis nostris la misión de sus embajadores Gatell y Pinós ante las autoridades venecianas, solicitándoles que a ellos, a su séquito, escuderos, familia y objetos protegiesen y ayudasen para poder llevar a buen término el cometido encomendado. La carta fue dirigida a los aliados italianos, entre quienes se contaban algunos de aquéllos con los que contactó a finales de 1346 con objeto de establecer una alianza contra Génova: Francesco y Jacomino de Padua, Moscino de Scala, señor de Verona y Vicenza, Giovanni Visconti, arzobispo de Milán, y el marqués de Monferrato $^{52}$. Ese mismo día el rey de Aragón escribía a Andrea Dandolo, dux de Venecia, informándole del nombramiento de embajadores que enviaba a su corte y el motivo de su presencia, solicitándole admitiese a los dichos legados en calidad de tales y ante ellos ratificase los términos del tratado ${ }^{53}$. Los embajadores aragoneses no sólo debían hacer acto de presencia para escuchar la ratificación del acuerdo y obtener el documento acreditativo de ello, sino que como comisionados plenipotenciarios habían de entrevistarse con el $d u x$ y tratar de cuestiones relativas a la guerra que pronto se iniciaría en actuación conjunta. La liga signada en Perpignan dejaba muchos aspectos susceptibles de renegociación, como la posibilidad de aumentar o aminorar la armada. Para ello Pedro IV dictó unos capítulos que sus nuncios habían de hacer llegar a la autoridad veneciana. Afortunadamente también han llegado hasta nosotros.

1. Previa salutación, Gatell y Pinós habían de informar al $d u x$ que su misión era la de requerirle que junto a sus consejeros procediese a confirmar y corroborar el pacto establecido tiempo atrás entre el Común veneciano, de la mano de Giovanni Steno, y la Corona de Aragón contra la República de Génova. Dicha confirmación habría de realizarla de acuerdo a lo establecido

\footnotetext{
${ }^{51}$ Giuseppe Meloni, Genova e Aragona, pp. 68-71. Aunque Maria Ines Melero, a través de la documentación veneciana, refiera que el primer pago se activa al año siguiente. María Inés MELERO FERNÁNDEZ, Fondos medievales, regesto 7.

${ }^{52} \mathrm{ACA}, \mathrm{C}$, reg. 556, f. 55v. (1351, junio, 4).

${ }^{53} \mathrm{ACA}, \mathrm{C}$, reg. 556, f. 56r.
} 
en la alianza, es decir, redactando dos documentos idénticos para conocimiento de cada una de las partes.

2. Habían de apuntarle asimismo que el rey de Aragón iba a poner todo de su parte para el escrupuloso cumplimiento de los capítulos de la liga, y que como los genoveses armarían una flota, la armada de la coalición había de estar dispuesta en el mar durante el tiempo estipulado en el acuerdo. Pedro el Ceremonioso pedía al $d u x$, a través de sus embajadores, que designase a un diplomático para residir de continuo en sus dominios, con potestad para decidir, en connivencia con él, acerca del incremento o aminoración de la flota, según se había convenido en uno de los capítulos del acuerdo, o para hacer lo que se considerase útil en cada momento, dado que la lejanía de los lugares donde podría activarse el conflicto hacía necesario que la toma de decisiones fuese lo más rápida posible.

3. En el caso de que la persona designada por la Serenissima considerase conveniente aumentar el número de barcos de la coalición, el dinero que los venecianos habrían de comprometer sería el correspondiente al incremento, habiendo de satisfacerse igualmente en Avignon y no en Venecia, hecho que retardaría el pago al tiempo que podría suponer daño o peligro a la flota.

4. El rey de Aragón proponía al $d u x$ un modo para conseguir que la guerra con Génova fuese rápida, suponiendo la victoria sobre el enemigo. Pedro IV era de la creencia de que los genoveses tenían dos opciones estratégicas. Una, la de construir y fletar una gran armada. Y una segunda, no hacerlo o de hacerlo que ésta fuese modica. En este segundo caso, a juicio del rey de Aragón, no habría que modificar ninguna de las directrices marcadas en los capítulos del acuerdo firmado en Perpignan. Con esta estrategia, manteniendo Venecia su flota en Oriente y la Corona de Aragón la suya en Occidente perjudicarían los intereses de los genoveses hasta el punto de sacarlos de la navegación. Sin embargo, en el caso de que los ligures se inclinasen por construir una gran armada para hacer frente a la coalición véneto-aragonesa, Pedro IV consideraba que la Serenissima habría de poner en juego una escuadra similar. El rey aragonés entendía que de hacerlo así, ambas potencias con sus respectivas flotas no sólo resistirían a los genoveses, sino que los derrotarían. En definitiva, su propuesta era hacer aquello que se hiciese desde Génova. Asimismo, entendía que resultaba conveniente establecer un punto común de encuentro para las dos flotas en un puerto de la isla de Sicilia, para que conjuntamente pudiesen perseguir a la escuadra genovesa a cualquier parte a la que pudiera ir, y en el caso de que les 
estuviese esperando protegerse. De este modo, era firme creencia del rey aragonés que la victoria caería de su lado y se llegaría al final del conflicto con la firma de una paz.

En el supuesto de que los genoveses no quisiesen fletar ninguna armada, atendiendo a lo costoso de una flota de esa magnitud, y a la creencia del rey de Aragón de que la economía de la república ligur no era buena en esos momentos -cum sint pauperes et non peccunia habundantes-, la guerra, según la lectura de Pedro IV, sería breve por los mentados problemas económicos -cum magna dificultate faciunt id quod faciunt dirá el aragonés-. Si decidiesen optar, sin embargo, por la construcción de una gran armada y activar el conflicto, aun dudando de poder costearla, y quisiesen enfrentarse contra una sola de las flotas aliadas antes de que coincidiesen las dos, venecianos y catalanes habrían de estar alerta y procurar que tal hecho no ocurriera. En buena lógica entendía el Ceremonioso que si la flota ligur fuese derrotada por una de las dos armadas de la colación la guerra finalizaría en el acto. Pero si en cambio fuesen los genoveses quienes derrotasen a una de las dos escuadras, la otra, muy reforzada y con ventaja, podría enfrentarse al enemigo y vencerlo, ya que es de suponer que habría quedado mal parado del primer encuentro.

Apuntarían, asimismo, los embajadores aragoneses a sus interlocutores italianos que la flota que el rey Pedro tenía el encargo de construir no podría estar a punto en la fecha marcada en la alianza - como se demostraría-, por dos razones. Una primera refería a que las galeras destinadas a esa armada necesitaban de gran reparación, dado que muchas de ellas se encontraban inservibles para la navegación. A ello se unía la falta de profesionales en la restauración de embarcaciones, maestros y calafates, desde los tiempos de la peste negra de 1348. De mostrar sorpresa o escepticismo los venecianos, podrían tener cumplida información a través de los embajadores que habían girado a tierras catalano-aragonesas, quienes, sin duda, decía Pedro IV, les corroborarían como verdadera la noticia que se les transmitía. La segunda de las razones era que tanto Pedro IV como Giovanni Steno, el embajador del $d u x$ en la Corte aragonesa, coincidían en que las dieciocho galeras que establecía la alianza militar contra Génova era un número claramente inferior al que los genoveses iban a poner en liza y que su no incremento podría ocasionar peligros y daños irreparables, habiéndose de aumentar en seis más. De esas seis embarcaciones, Venecia habría de pagar cuatro, a razón de los dos tercios establecidos en la alianza, en el lugar habilitado para los pagos, Avignon. Pero si por causa del armado de esas seis 
galeras, alcanzando la flota el número de veinticuatro, se pudiese producir algún retardo en la activación de la armada, como por esas cuatro naves no se había recibido dinero alguno modo simili dilatatur.

Al conocerse, una vez establecida la alianza y dictados los capítulos, que la república ligur había decidido armar una flota que quedaría activa para la navegación a mediados del mes de junio, y según las informaciones con que se contaba alcanzaba las treinta galeras, Pedro IV consideró la posibilidad de que se construyesen dos flotas, pues atendiendo a esta información la armada veneciana no era tan fuerte en número de galeras para enfrentase y vencer a la genovesa. El rey aragonés apuntaba, a razón de las noticias que había obtenido de los movimientos estratégicos del enemigo, la conveniencia de que los venecianos procediesen del modo que sigue para que la guerra cayese de su lado: habrían de apresurarse a dotar a sus embajadores de potestad para negociar el aumento del número de embarcaciones que compondría la flota, y para ello habían de enviar de forma inmediata dinero para pagar el incremento de la misma. Sospechando que la armada genovesa estuviese dispuesta para navegar en el citado mes de junio, y aunque anticipase en un mes su puesta a punto, no podría hacer demasiado daño, dado que las galeras del rey de Aragón estarían listas para perseguirla donec invenissent illud; en su defecto, a su retorno la flota aragonesa interceptaría y derrotaría a los ligures con total seguridad. Pensando en que la armada genovesa navegase versus maria Romanie aut ingredi pelagum venetorum, se consideraba que aunque a la ida se causasen ciertos daños éstos serían tolerables. Y como la escuadra del rey de Aragón podía estar a punto enseguida el proceso había de duplicarse, es decir, que de una parte de esa gente armada se ocupase Pedro IV y de la otra lo hiciese Venecia. El monarca aragonés contaba con mil florines para dedicar al armado de cada galera, y no más, cuantía que recibía de Venecia según lo establecido en la alianza. Atendía el rey, entonces, que si esto se podía hacer por duplicado la utilidad de la flota de la coalición sería mayor, dado que estaría lista mucho antes. Esgrimía el Ceremonioso una razón logística, y es que muchas de las marítimas de la Corona de Aragón estaban dentro del dominio señorial, donde el rey no podía armar barcos. Por ello apuntaba que eso había de hacerse en un único lugar, en un puerto, y en un plazo no superior a seis meses, ya que de lo contrario los costes se encarecerían notablemente. En el supuesto de que los embajadores venecianos hubieran necesidad de establecer consultas con el $d u x$ al respecto de este extremo, dispondrían de veinticinco días para llegar hasta la ciudad de los canales, diez para realizar las consultas pertinentes, y otros veinticinco para 
regresar, lo que suponía dos meses. Todo ello era con el ánimo de conseguir el dinero necesario para la ampliación de la armada. De este modo, con una flota más numerosa, el rey de Aragón estaba dispuesto a ponerla a navegar y dirigirla lo más rápido que pudiese in partibus Sicilie y desde esa base buscar y derrotar al enemigo genovés. Para el buen fin de la guerra Pedro IV entendía indispensable esa inyección suplementaria de dinero veneciano, ya que tanto para reparar como para la construcción de galeras, remos, jarcias y la adquisición de las armas necesarias era imprescindible más numerario. Insistía el Ceremonioso a la República de San Marcos en un hecho, y es que bajo ningún concepto combatiese sola a los genoveses, a no ser que contase con clara y manifiesta ventaja o en el caso de que la flota aragonesa se encontrase en Sicilia para apoyarla, pues de este modo las dos escuadras juntas derrotarían al enemigo ligur con seguridad.

Pedro IV consideraba que el Común veneciano debería aceptar su propuesta para la guerra, pues de otro modo la flota genovesa causaría desgracias y daños en las veinticuatro galeras que se preparaban. Por todo ello solicitaba a sus embajadores que acelerasen la marcha para informar lo más rápido que pudiesen al $d u x$ Dandolo, habiendo de hacer hincapié en el incremento del número de barcos de la flota ${ }^{54}$.

El 12 de julio, en el interior del palacio ducal y en presencia de los magnates de la república así como de Rafaino de Caresini y de Nicola de Lambertis, notarios de la ciudad de Venecia, Andrea Dandolo junto a sus consejeros aprobó y ratificó, nemine discrepante, en toda su extensión los capítulos de la alianza establecida con la Corona de Aragón, jurando la observancia de la liga ante los Evangelios y los embajadores aragoneses desplazados a tal efecto, Azbert de Gatell y Bertrand de Pinós, que recibieron documento firmado de tal conformidad ${ }^{55}$.

En ese tiempo la fluidez en las comunicaciones entre los aliados fue nota predominante. La Corona de Aragón llevaba cierto retraso en los preparativos de la armada conjunta, mientras que Venecia ya había iniciado acciones bélicas contra los ligures en el Levante mediterráneo. En uno de esos frecuentes correos Pedro el Ceremonioso se dirigió al veneciano alabando las dotes de su embajador Steno, que calificaba de persona efectiva, experta y

${ }^{54} \mathrm{ACA}, \mathrm{C}$, reg. 556, ff. 55v.-59r. Una visión resumida de estos capítulos en Giuseppe Meloni, Genova e Aragona, pp. 71-72.

${ }^{55} \mathrm{ACA}, \mathrm{C}$, reg. 556, ff. 64r.-v. 
prudente, fundamental en el establecimiento de la alianza entre ambas potencias. El rey de Aragón encarecía a su homólogo italiano a recompensarle, si lo creía oportuno, por sus merecidos méritos y los servicios prestados ${ }^{56}$. Y al tiempo hacía lo propio a los custodios de las fronteras de la Corona, a quienes controlaban la extracción de las cosas prohibidas y a sus amigos, informándoles de la marcha del embajador Steno a la ciudad de los canales acompañado de su familia así como de ricos presentes, entre los que se contaban rocines, armas, arneses, vajillas de plata y otras cosas, y solicitándoles ayuda y protección en el viaje ${ }^{57}$.

Con la seguridad de que la alianza era firme, y aunque los preparativos iban despacio, el 3 de agosto Pedro IV dirigió una carta de desafío a Génova declarando la guerra ${ }^{58}$.

Tras el retorno de Giovanni Steno a Venecia esa primavera quedó como embajador permanente del $d u x$ en la corte aragonesa Giovanni Gradenigo. Este legado, mencionado por Zurita de forma errónea como artífice de la firma de la liga véneto-aragonesa, había hecho saber al Ceremonioso la conveniencia de aumentar el número de barcos de la armada que se estaba preparando en sus puertos en otros seis si realmente se quería damnificar a Génova. De una parte y de otra se llegó a la conclusión de que la flota inicial quedaba corta en número frente a un enemigo tan peligroso. Génova, no lo olvidemos, era una potencia naval, de ahí que en pocos meses a las dieciocho naves iniciales se uniesen doce más. A mediados de agosto, el rey de Aragón escribía a Andrea Dandolo para apuntarle que el número de embarcaciones con que contaría la armada que él fletaba era de treinta galeras, y que una vez en el agua se dirigirían a Sicilia, teniendo como base el puerto de Messina, adonde habían de llegar en el mes de septiembre. Pero al tiempo indicaba a Dandolo que el número de galeras que debían armar los venecianos era de cuarenta; con ello la flota conjunta sería invencible. El monarca aragonés se comprometía a que sus treinta galeras armadas estuvieran en plazo

${ }^{56} \mathrm{ACA}, \mathrm{C}$, reg. 556, f. 59v. (1351, julio, 30).

${ }^{57}$ ACA, C, reg. 556, f. 59v. (1351, julio, 30).

${ }^{58}$ El primero de junio Pedro IV comunicaba a los catalanes residentes en Romania la revuelta sarda apoyada por Génova y la alianza con Venecia para proceder contra los ligures. Antoni RUBIÓ I LLUCH, Diplomatari de l'Orient catalá (1301-1409). Col lecció de documents per a la història de l'expedició catalana a Orient i dels ducats d'Atenes i Neopatria, Barcelona, 2001, doc. CXCIX. En lo que refiere a hechos de guerra G. Meloni apunta que ya se producen el día anterior a la comunicación de la declaración oficial a Génova. Giuseppe MELONI, Cenni sulle relazioni tra Genova e l'Aragona nel secolo XIV (1351-1360), "VIII Congreso de Historia de la Corona de Aragón. II. La Corona de Aragón en el siglo XIV", volumen tercero (1973), p. 120. 
en el lugar acordado; no obstante las veinticuatro ya armadas navegarían a aguas genovesas para damnificar al enemigo en su camino hacia Sicilia ${ }^{59}$.

Pons de Santa Pau fue nombrado capitán de la flota a mediados de marzo ${ }^{60}$, y sus órdenes eran dirigir la armada, una vez unida a la veneciana, a aguas del Egeo. De nuevo es el cronista Zurita quien siguiendo el relato de la Crònica de Pedro IV nos ofrece la ruta tomada por Santa Pau, que partiendo de Mahón a principios de octubre, con gran retardo respecto de lo establecido $^{61}$ y con escala en Cagliari se unió en Messina con Panerazio Giustinian, su homólogo veneciano que capitaneaba veinte galeras. Tras una travesía bastante accidentada en la que se perdió alguna nave, a las dos flotas, en buen orden, navegando hacía Constantinopla se les unieron catorce embarcaciones venecianas y cuatro valencianas comandadas por Bernat de Ripoll. La cuenta del número de barcos, entre ligures y de la alianza, ha dado lugar a una lotería de números que huelga referir ${ }^{62}$. Zurita nos narra con gran dramatismo el cruel enfrentamiento entre las dos armadas en aguas del Bósforo en medio de una gran tormenta en la que el viento y la fuerza del agua hacían más daño que el enemigo. Sus palabras no dejan lugar a dudas:

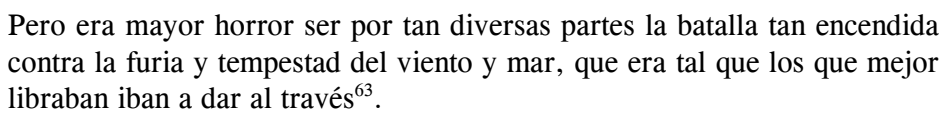

La batalla naval de Pera ${ }^{64}$, sucedida la fría noche del 13 febrero de 1352, supuso un gran quebranto a la armada de la coalición véneto-aragonesa, causando la pérdida de muchas de las embarcaciones del rey de Aragón con p. 86.

${ }^{59} \mathrm{ACA}, \mathrm{C}$, reg. 556, ff. 59v.-60r. (1351, agosto, 14). Giuseppe MELoni, Genova e Aragona,

${ }^{60}$ Rafael GALlOFRÉ y José TRENCHS, Almirantes y vicealmirantes de la Corona de Aragón (1118- 1462), "Miscel-lània de Textos Medievals", 5 (1989), doc. 88. Este oficial ya había desempañado cargos militares en Cerdeña en tiempos de la revuelta, actuando por un tiempo de gobernador sustituto. Giuseppe MELONI, Genova e Aragona, pp. 40 y 46.

${ }^{61}$ Giuseppe Meloni, Genova e Aragona, pp. 85-100.

${ }^{62} \mathrm{G}$. Meloni, que analiza esas cifras poniéndolas en confrontación con las de todos los autores que trataron la cuestión hasta la publicación de su estudio, apunta siempre a una ligera ventaja de la flota véneto-aragonesa. Ibídem, p. 100, nota $\mathrm{n}^{\mathrm{0}} 65$.

${ }^{63}$ Jerónimo ZURITA, Anales, 4, VIII, XLVI, p. 211.

${ }^{64} \mathrm{~A}$ este respecto cf. Michel BALARD, A propos de la bataille du Bosphore: l'expédition génoise de Paganino Doria à Constantinope, 1351-52, Travaux et Memoire IV, Centre de Recherches d'Histoire et Civilisation Byzantines, Paris, 1970, pp. 431-469. 
sus tripulaciones y la muerte de dos de sus capitanes, el vicealmirante Ripoll y el comandante de toda la flota Pons de Santa Pau. Los daños sufridos por la parte veneciana fueron igualmente grandes ${ }^{65}$, pereciendo altos mandatarios de su marina, entre ellos su comandante Giustinian, Stefano Contarero, proveedor de la señoría, Bonanato Bembo y Giovanni Steno, quien fuera el artífice de la liga ${ }^{66}$. La batalla del Bósforo no fue desde luego una gran victoria para las armas del Casal de Barcelona, pese a la información que Santa Pau ofrecía por carta al Ceremonioso enfatizando una obtenta victoria ${ }^{67}$; tampoco lo supuso para Génova. Zurita, panegirista de los hechos de Aragón, sólo menciona en sus Anales la derrota genovesa, mientras que Pedro IV recoge en su Crònica las grandes pérdidas materiales y humanas que el choque ocasionó a Corona de Aragón, aun reconociendo que la república ligur sufriese mayor descalabro ${ }^{68}$. Es decir, del lado catalano-aragonés si fue algo que no derrota se trató de una victoria pírrica cuando no "duptosa" al decir de R. Tasis ${ }^{69}$. La historiografía italiana ofrece una visión algo distinta. Y así, mientras C. Diehl, que escribe desde el observatorio veneciano, refiere a una victoria indecisa ${ }^{70}$, F.C. Lane narra con bastante detalle los hechos del trágico encuentro de las armadas en las aguas bizantinas, apuntando que si se hubiese de señalar algún vencedor éste sería Génova, aunque sólo desde un punto de vista estratégico, ya que la liga véneto-aragonesa no consiguió lo que la guió hasta aquellas latitudes ${ }^{71}$. J.J. Norwich es de idéntica opinión, calificando la victoria genovesa de "técnica" y la derrota veneciana de heroica, más si cabe

${ }^{65}$ Frederic C. LANE, Venice, p. 178.

${ }^{66}$ Crònica de Pere el Cerimoniós, pp. 1113-1114. Jerónimo ZURITA, Anales, 4, VIII, XLVI.

${ }^{67}$ Antoni RUBió I LluCH, Diplomatari, doc. CCII. 211-212.

${ }^{68}$ Crònica de Pere el Cerimoniós, p. 1114. Jerónimo ZuRITA, Anales, 4, VIII, XLVI, pp.

${ }^{69}$ Rafael TASIS I MARCA, Pere el Cerimoniós i els seus fills. Historia de Catalunya. Biografies Catalanes, 7, Barcelona, 1980, p.54.

${ }^{70}$ Carlos DieHL, Una república de patricios, p. 61

71 "Both sides claimed to have won the battle, but strategically the victory certainly lay with the Genoese, for the Catalans and Venetians withdrew. They had lost too much to try further assault on Pera, especially since the Genoese were receiving not only supplies but soldiers from the Sultan of the Ottoman Turks, Orkhan I, who ruled all the eastern side of the Bosphorus and the Sea of Marmora. Orkhan was looking towards expansion into Europe also. He did not want to see either the Byzantine empire or the Venetian naval power strenghtened. After the allied fleet left, the Byzantine Emperor felt he had no alternative but to make peace with the Genoese and allow them to fortify Pera and the hill of Galata as they wished. Thereafter, the naval action in the Aegean consisted of much capturing of individual Genoese ships by Venetians and vice versa". Frederic C. LANE, Venice, p. 178. 
tras la descoordinación de los catalanes y la sorprendente retirada bizantina en los prolegómenos de la contienda ${ }^{72}$. Así lo escribe G. Meloni ${ }^{73}$ y lo destaca F. Giunta, al señalar que el quebranto de su armada en los mares de Oriente dirigió a Pedro IV a focalizar su interés estratégico en el Mediterráneo Occidental $^{74}$. De desastre, fuese realmente por vía de la derrota o de la tempestad, fue calificado el encuentro naval por el rey de Aragón, y así lo hará constar de modo implícito a sus aliados venecianos, al considerar que los hechos de Pera no habían sido sino un exceso de generosidad por su parte que estaba dispuesto a corregir.

Lo cierto es que pocos días después de esa gran batalla, de la que todavía no se tenía conocimiento en los dominios del rey de Aragón ${ }^{75}$, Pedro IV temió por la integridad de su flota al conocer que en Génova se estaban armando diez galeras. La lejanía de las embarcaciones catalano-aragonesas, que navegaban in partibus Romanie, y el aumento del potencial enemigo, le llevaron a solicitar al aliado veneciano que dispusiese que las galeras del rey de Aragón navegasen juntas et inseparate con el fin de no sufrir daños por parte del enemigo ${ }^{76}$. Similar recomendación de cautela en extremo cursaba al capitán de la armada, Pons de Santa Pau, a quien le hacía saber la amenaza genovesa y le solicitaba que manejase saviament la flota cuando hubiera de regresar para evitar daños ${ }^{77}$. Ese incremento de la potencia naval genovesa

${ }^{72}$ John J. NoRwich, A History, pp. 217-218.

${ }^{73}$ Giuseppe Meloni, Genova e Aragona, p. 110.

${ }^{74}$ "L'avvenimento negativo, che ebbe supersititi soltanti due galere catalane delle ventitré allestite e poste al comando di Ponç de Santa Pau, servì a rimettere Pietro IV sul tradizionale binario della politica aragonese geograficamente limitato al bacino occidentale del Mediterraneo". Francesco GIUNTA, La politica mediterranea di Pietro il Ceremonioso, "Pere el Cerimoniós i la seva època", Barcelona, 1989, p. 62. Esta será la tónica de la historiografía italiana. Cf. Marco TANGHERONI, Commercio e navigacione nel medioevo, Roma-Bari, 1996, p. 385.

${ }^{75}$ Zurita refiere en su Crónica que sería en mayo cuando la noticia llegó a oídos de Pedro IV. Jerónimo ZURITA, Anales, 4, VIII, XLVIII, p. 217.

${ }^{76}$ ACA, C, reg. 556, f. 60v. (1352, febrero, 20). G. Meloni apunta una comunicación anterior, de 22 de enero, en la que ya le hacía saber que los ligures iban a poner en liza diecinueve barcos más. Giuseppe MELONI, Genova e Aragona, p. 106. Quizá fuese una mala cuenta por parte del servicio de espionaje catalano-aragonés, o bien, lo más peligroso para los intereses del Ceremonioso, que la comunicación de febrero refiriese a otras galeras -"decem galee que parate et armate erunt in brevi".

${ }^{77}$ ACA, C, reg. 556, f. 60v. (1352, febrero, 19). 
atormentó a Pedro IV, dado que podía poner en peligro a sus embarcaciones ${ }^{78}$. Dispuso entonces el Ceremonioso un aumento de la flota en doce naves, que obviamente comunicó por escrito a Andrea Dandolo así como a través de una embajada que le dirigía encabezada por Bernat Oliver. Oliver fue comisionado el 19 de febrero, y junto a los obispos de Mallorca y Barcelona, Antoni y Miquel respectivamente, había de exigir y percibir del $d u x$ y Común de Venecia los treinta y dos mil florines con que habían de contribuir para el armado de esas doce galeras, de cuya financiación los venecianos corrían con las dos terceras partes, que era el monto que se les solicitaba ${ }^{79}$. Para asegurar el viaje de su embajador, Pedro IV volvió a reclamar la colaboración y ayuda de sus amigos italianos, que habían de proteger la comitiva de su legado con destino a Venecia, mostrándose de nuevo los nombres de los señores de Padua, Verona, Vicenza y el del arzobispo Visconti de Milán ${ }^{80}$. También el de un viejo amigo veneciano, Giovanni Steno, a quien el rey Ceremonioso calificaba de militi de casa nostra, pues como nos relata en su Crònica le armó caballero ${ }^{81}$, y solicitaba su apoyo para que los asuntos que llevaban a Oliver hasta su ciudad los resolviese felizmente y el regreso a la Corte aragonesa fuese rápido ${ }^{82}$. La misiva enviada a éste tiene fecha de $20 \mathrm{de}$ febrero, siete días después de la batalla de Pera donde Steno había caído. Otros venecianos también fueron avisados por el rey de Aragón de la embajada de Oliver, caso de los hermanos Franceschino Cocco, de la casa del rey, y Jacobino de Damello, o de Nicola de Lambertis, escribano del $d u x$, a quienes se solicitaba que introdujesen al embajador aragonés en la Corte ducal y apoyasen su misión ${ }^{83}$.

Afortunadamente conocemos los capítulos de la embajada que llevó a Bernat Oliver a tierras italianas. Éstos referían exclusivamente a la información que debía transmitir al $d u x$ y Común de Venecia al respecto del armado de las doce galeras que Pedro el Ceremonioso deseaba realizar in

\footnotetext{
${ }^{78}$ De hecho así sucedió. Zurita refiere que algunas de las naves que regresaban a Cataluña, una en concreto que portaba el cuerpo del quien había sido artífice de la victoria naval sobre Génova, Pons de Santa Pau, fue capturada por la flotilla ligur compuesta por esas diez galeras. Jerónimo ZURITA, Anales, 4, VIII, XLVIII, p. 218.

${ }^{79} \mathrm{ACA}, \mathrm{C}$, reg. 556, f. 62r.-v.

${ }^{80} \mathrm{ACA}, \mathrm{C}$, reg. 556, f. 63r. (1352, febrero, 20).

${ }^{81}$ Crònica de Pere el Cerimoniós, p. 1112.

${ }^{82}$ ACA, C, reg. 556, f. 63v. (1352, febrero, 20).

${ }^{83} \mathrm{ACA}, \mathrm{C}$, reg. 556, f. 63v. (1352, febrero, 14).
} 
terra et dominacione sua para asegurarse el éxito militar contra Génova. Después de mostrar a las autoridades de la Serenissima las credenciales de su nombramiento, Oliver pasaría a ofrecer la información que había llegado hasta Pedro IV, y que el rey de Aragón consideraba fidedigna, referida al incremento de la flota genovesa en diez galeras que muy pronto estarían prestas para navegar, creyéndose que en ese mes de febrero ya lo estarían. Por ello, y con el ánimo de que los súbditos de la Corona de Aragón y de la república adriática pudiesen navegar por los mares sin temor a ser asaltados, el rey de Aragón proponía que fuesen armadas doce galeras por espacio de cuatro meses in diccione sua dentro de los pactos habidos entre ambas potencias. El rey de Aragón se haría cargo del armado de dichas embarcaciones, que pagarían los venecianos en dos terceras partes, según lo establecido en la liga del año anterior. El dinero veneciano había de llegar hasta Avignon, de tal modo que a medidos de abril ya estuviese en Barcelona en manos de Pedro IV. La necesidad de aumentar el número de naves derivaba del incremento genovés, por un lado, así como que el rey de Aragón ya no contase con más embarcaciones, al tenerlas todas en servicio de los venecianos. Tras la exposición, Oliver debía solicitar el placet del aliado e insistir en la premura de tiempo con el fin de que la armada de la coalición quedase al completo y activa lo antes posible ${ }^{84}$.

Dicho esto, el rey presentaba una batería de dudas que se podrían producir respecto de la embajada y que habrían de ser defendidas por su legado. Por ejemplo, si por un caso el $d u x$ y Común de la república italiana argumentasen y pusiesen in compoto las galeras que echaban a faltar de las treinta que componían la flota y que no navegaron ad dictas partes Romanie, Oliver había de responder que el rey de Aragón armó y pagó las treinta galeras de la siguiente forma. De esas treinta galeras salieron y navegaron ultra farum Messine veintisiete naves completamente armadas, que debían juntarse con la flota veneciana, computada una entre tales que per temporis fortunam naufragó en el lugar de Ampolla; una segunda galera, armada al

\footnotetext{
${ }^{84} \mathrm{~A}$ finales de marzo, y desconociendo todavía el resultado del encuentro producido en aguas bizantinas, Pedro IV escribía a Andrea Dandolo para ratificarle la mala nueva de que los ligures tenían previsto armar de inmediato en la ciudad de Génova diez galeras, que estarían listas en breve, lamentarse de que en sus tierras y sus mares ya no contase con más barcos que emplear en la guerra e informarle del armado de esas doce nuevas galeras, con el fin de haber recabado la financiación veneciana a mediados de mayo. El encargado de aclarar cualquier cuestión al respecto era Bernat Oliver, a quien debía escuchar a su llegada. Esta carta nos indica claramente que el embajador aragonés no se encontraba en Venecia en esas fechas. ACA, C, reg. 556, f. 60v. (1352, marzo, 30).
} 
completo en la ciudad de Tarragona y pagada, que naufragó también en el cabo de Salinas insule Maioricarum producto de un infortunio; y asimismo una tercera, igualmente armada y pagada, que regresaba a Cataluña y en su viaje de retorno per costeram Janue fecit viam stolei dicti domini regis, sabiendo ciertamente que esa nave había estado en Cerdeña non est diu -hacía poco tiempo-. El rey de Aragón no supo si esta última embarcación si sequta fuit stoleum suum vel si damnificat januensibus citra farum Messine. Pero, fuese como fuese, entendía que los venecianos debían computar la galera como armada, dado que según se establecía en los acuerdos firmados entre las partes el año anterior la flota aragonesa no debía navegar más allá bucham de faro, cosa que hizo en servicio del $d u x$ y Común de Venecia. Por tal, si la nave no hubiese transitado por esas aguas con el resto de la armada aragonesa para damnificar al enemigo genovés, hubiese entrado en la cuenta de aquéllas que los venecianos habían de sufragar. Pedro IV, no obstante, entendía que se pudiesen computar veintinueve, y no menos, dado que una galera quedó sin capitán y cuando llegó a Mallorca fue desmantelada, aunque sus tripulantes fueron repartidos entre las embarcaciones que necesitaban hombres. Cuando años después el rey Ceremonioso manda redactar su Crònica, llegado a este pasaje refiere que fueron veinticuatro las galeras armadas, y sólo veintiuna las que portó Santa Pau, saliendo las tres restantes algo después desde Valencia capitaneadas por el vicealmirante Bernat Ripoll ${ }^{85}$. Este error de cálculo quizá pudiese ser imputable a la distancia temporal que media entre uno y otro hechos.

Otra de las cuestiones atendía a que los venecianos podían dudar de que la flota armada por el rey de Aragón, que se encontraba entonces in partibus Romanie, no fuese financiada en la parte que a éste correspondía transcurridos los cuatro meses establecidos. A este respecto Bernat Oliver debía transmitirles confianza, así como recordarles que la flota pasó a navegar a aguas de más allá del Estrecho de Messina en auxilio y servicio de Venecia aun cuando no estaba estipulado en los acuerdos. Y aunque en las disposiciones de la liga se estableció que esas galeras podrían transitar por tales aguas si los capitanes de ambas escuadras se concordaban para ello, cosa que, obviamente, hicieron, el embajador de Pedro IV habría de responder con que la alianza militar véneto-aragonesa tenía vigencia mientras que la flota estuviese pagada, y que la capitanía del responsable aragonés de la misma

\footnotetext{
${ }^{85}$ Crònica de Pere el Cerimoniós, p. 1112.
} 
estaba hecha por cuatro meses. Si los barcos del rey de Aragón navegaron por las citadas aguas orientales fue, entre otras razones, porque se había pagado la parte que el Ceremonioso tenía comprometida para la financiación de la flota. Por ello entendía que si los venecianos, transcurridos los dichos cuatro meses, deseaban seguir contando con la armada quod ipse solveret aliquid in predictis percipue, dado que el capitán de la flota lo era sólo por ese tiempo y una vez transcurrido perdía cualquier potestad de gobierno y dirección sobre la misma. No obstante, aunque siguiese ejerciendo como tal durante el retorno a sus bases de la Corona de Aragón no estaba autorizado a proceder de otro modo. Y de esto, decía Pedro IV, dictus nuncius - refiriéndose a Oliver-si necesse fuerit, potest facere fidem.

En el caso de que los venecianos predicta omnia dijeren o alegaren, Bernat Oliver les diría quod ipsi darent causam et materiam sperarent; que si de otro modo pedían auxilio el rey de Aragón no consentiría que sus barcos navegasen más allá de los lugares establecidos en la alianza firmada el año anterior. A este respecto, se había de recordar a las autoridades de la Serenissima que Pedro el Ceremonioso envió omnia maria spoliata sus galeras, quedando sus súbditos y sus tierras en gran peligro, pues al proceder en la ayuda del aliado se había descuidado la defensa de sus islas, en clara alusión a Córcega y Cerdeña, sin desdeñar tampoco al reino de Mallorca. De aducir Venecia los grandes gastos que realizaba en la guerra contra la república ligur, cuyas embarcaciones se encontraban in partibus Romanie y de las que no se debía dudar, Bernat Oliver había de responder con la idea anterior, es decir, que atendiesen a que el rey de Aragón al acudir con su armada en ayuda de Venecia a aguas del Egeo descuidaba sus marítimas y sus gentes, que podían ser damnificadas por esas diez galeras que ahora Génova ponía a flote. Dicho esto, el embajador Oliver había de enfatizar en la solicitud de financiación en la parte que correspondía a Venecia para el mantenimiento de la armada, es decir el pago de doce galeras para cuatro meses, según lo establecido, deducta dicta galea viginti octo mille floreni de Florencie boni et fini auri rectique ponderis.

Como en la flota del rey de Aragón algunas de esas embarcaciones armadas regresaron mucho tiempo antes de que lo hiciese el grueso de la escuadra, el pago de tales naves había de ser igual al del resto, mil florines de oro pro panatica. La cantidad a alcanzar era de seis mil florines, que serían entregados a Francesc de Finestres y a Guillem Morei, miembros de la 
armada del lado aragonés ${ }^{86}$. De tal cantidad Venecia había de contribuir con las dos terceras partes, o lo que es lo mismo cuatro mil florines. Oliver, por tanto, había de reclamar al dux y Común que además de los veintiocho mil florines arriba señalados incluyesen en el pago avignonés esos cuatro mil. De entender Venecia que no le competía la satisfacción de esas galeras donec omnes insimul recederent, se le habría de responder que debido a sus prisas, las de la república italiana, por activar la liga antigenovesa, el rey Ceremonioso construyó su armada en diversos puntos de su dominio, como Barcelona, Valencia, Mallorca, Tortosa, Tarragona, isla de Cerdeña y Colliure. Es por ello que todas las galeras no se pudieran armar juntas nec eis fieri soluciones equaliter, imo fuerunt ipsorum diversitates. Es por ello también que los venecianos debían proceder al pago de los dos tercios que les correspondían, los citados cuatro mil florines ${ }^{87}$.

Desde luego, en esos capítulos Pedro el Ceremonioso hace hincapié en un hecho principal, percibir el total del porcentaje establecido con la Serenissima en lo que refiere a la financiación de la flota de la coalición siguiendo los criterios marcados en los pactos de Perpignan. Y es que puede que intuyese inconvenientes por parte del aliado para remunerar las galeras armadas en las marítimas catalano-aragonesas. De entrada, pese a que el 15 de febrero anterior la autoridad veneciana nominase a dos embajadores para acudir hasta Avignon y rescatar cierto dinero que se adeudaba a la Serenissima para con él, en cuantía de 48.000 florines, salvar una de las entregas estipuladas en el acuerdo militar de 1351, y a que el propio Pedro el Ceremonioso enviase a Ferrer de Manresa a retirar ese dinero un mes después, a principios del año siguiente todavía no se había recibido un solo florín, siendo en abril cuando el obispo barcelonés, comisionado en Avignon desde enero, señalaba haber tomado 38.000 florines y 10.000 ducados por tal cuenta $^{88}$. Y, en principio, da la sensación de que tal pago refiere únicamente a las naves recogidas en el acuerdo de enero de 1351, no a los incrementos posteriores. Así lo constata también F.C. Lane, cuando indica que de las treinta embarcaciones enviadas por Pedro IV al Bósforo, sólo doce quedaban a cargo de Venecia, siendo las dieciocho restantes sufragadas a expensas

\footnotetext{
${ }^{86}$ Ambos, junto a los vicealmirantes de Cataluña, Valencia y Mallorca, Bonanat Descoll, Bernat Ripoll y Roderic de Sent Martí, componían el estado mayor de Pons de Santa Pau. Crònica de Pere el Cerimoniós, pp. 1112-1113.

${ }^{87} \mathrm{ACA}, \mathrm{C}$, reg. 556, ff. 61r.-62r.

${ }^{88} \mathrm{Cf}$. María Inés Melero FernándeZ, Fondos medievales, regestos 7 a 10.
} 
propias $^{89}$, lo que, en principio, choca con lo que expresa el monarca a sus legados.

La autoridad veneciana, quizá a través de la correspondencia que mantenía con sus embajadores en la Corte aragonesa, conocía de antemano de la posición del rey de Aragón y se adelantó a la presencia del nuncio Oliver a tierras de la Serenissima. Andrea Dandolo, en carta fechada el 3 de marzo y dirigida a Pedro IV, aceptaba de buen grado el armado de diez nuevas galeras en los dominios catalano-aragoneses para dar respuesta a la presencia del mismo número de naves de guerra fletadas por Génova; embarcaciones que se habían de armar por tres meses para perseguir a la escuadra genovesa allá donde se encontrase - tam Romanie quam alibi ubi dicte galee januensium navigassent-. El dux dio instrucciones a su embajador en tierras aragonesas, Giovanni Gradenigo, que de armarse esas galeras contribuiría con las dos terceras partes del coste de la operación, pagadero en Avignon, del modo convenido en la alianza de 1351. El rey de Aragón contestó a Venecia el 10 de abril, informando al $d u x$ que iba proceder al armado no de diez sino de doce nuevas galeras por espacio de cuatro meses, por las razones que le explicaría su embajador Bernat Oliver. El armado de esas naves sería amplio, con el fin de que los enemigos, que acababan de armar diez, no tuviesen ventaja, siendo necesario que se hiciese por cuatro meses, pues no encontraba a nadie qui pro minore tempore vellet galeas ascendere. Procedió a recordarle que entre los acuerdos de la liga de 1351 se establecía que mientras ésta estuviese vigente Venecia se comprometía a enviar cuatrimestralmente a la corte papal la parte de la financiación de la flota a ella adjudicada, doce galeras, dinero que ahora le requería para que la armada celeriter compleatur. Pedro el Ceremonioso se mostraba sorprendido de la petición veneciana de que las galeras que se armasen hubieran de servir para perseguir a la flota genovesa allá donde se encontrase, al entender que el requerimiento iba contra

${ }^{89}$ Frederic C. LANE, Venice, p. 176. Según este autor, Venecia sólo se comprometió al pago de doce embarcaciones de las treinta armadas. Si vinculamos el numeral a los tratos de 1351 hemos de pensar que todas las galeras que se armaron fuera de las dieciocho que se recogían en el pacto habían de ser pagadas por Aragón, lo que, desde luego, es contrario a lo establecido en los capítulos de la alianza. María Inés Melero, sin embargo, dentro de la colección de regestos documentales venecianos relativos al tema, apunta un texto fechado en septiembre de 1353 por el que Pedro IV reconocía haber recibido 13.300 florines que todavía se le adeudaban "por los gastos de cuarenta galeras por él armadas para la guerra contra los genoveses". Tal número de embarcaciones quizá refiera a las treinta citadas anteriormente más las diez/doce que pudiese haber armado tras el fracaso de Pera. Pero lo cierto es que en 1354 todavía coleaban deudas de la Serenissima respecto de las galeras armadas por la Corona de Aragón. María Inés MELERO FERNÁNDEZ, Fondos Medievales, regesto 10 a 13. 
lo establecido en los acuerdos de la alianza, como se podría observar de analizarse la redacción del texto. Claramente el monarca aragonés no deseaba navegar más allá del Estrecho de Messina - cum per nos inde fuimus rogati consensimus graciose quod galee nostre, in servicium et auxilum vestrum, transirent ultra bucam de faro-; y ello atendiendo a que todavía no tenía noticias de los sucesos de Pera. Exponía además a su homólogo Dandolo que aunque quisiera complacerle, el embajador veneciano que tenía destinado en su Corte carecía de potestad para negociar un aumento en el tamaño de la flota que se armaba en las marítimas del rey de Aragón. Para ello, exponía el Ceremonioso, le solicitaba la presencia inmediata de un nuncio plenipotenciario para proceder en ese asunto, de resultar realmente necesario y ser bien visto por ambas partes, tanto en lo que refiere al aumento del número de naves, al armado en sus marítimas y al hecho ser utilizadas en la persecución de los genoveses allá donde se encontrase su flota ${ }^{90}$. Al día siguiente, 11 de abril, Pedro IV escribía al embajador Oliver informándole de la carta enviada al $d u x$, de la que le mandaba traslado para su conocimiento, para señalarle que atendiendo a lo apuntado en esa carta y a la información que poseía procurats saviament e iverçosament los asuntos que tenía encomendados. Le refería que no dijese nada acerca de la paga de las galeras nostras que se encontraban en Romania referente a que si transcurridos los cuatro meses la parte correspondiente a la Corona de Aragón seguiría siendo satisfecha. En el caso de que se le requiriese respuesta al respecto, Oliver había de decir que desconocía ese extremo, que no había oído nada y que carecía de orden o poder para tratar la cuestión ${ }^{91}$.

El rey de Aragón, aún desconociendo el resultado del encuentro de las escuadras en el Bósforo, comenzaba a replantearse seriamente la presencia de sus barcos en aguas del Levante mediterráneo. Pedro IV argumentó para ello el texto del acuerdo militar con Venecia, en el que, efectivamente, se explicitaba que la armada de la coalición había de proceder en el espacio marítimo del Tirreno. Pero también lo es, y en esto se apoyaba la Serenissi$m a$, que la presencia naval ligur en el Mediterráneo oriental obligaba a la flota catalana a acudir a aquellas latitudes; y dicha obligación también quedaba

${ }^{90} \mathrm{ACA}, \mathrm{C}$, reg. 556, f. 65r.-v.

${ }^{91} \mathrm{ACA}, \mathrm{C}$, reg. 556 , f. $65 \mathrm{v}$. 
recogida en uno de los capítulos de la liga ${ }^{92}$. Es por ello que ambas potencias tenían razón en su requerimiento a la otra, y demuestra que el interés de cada una estaba en las antípodas del Mediterráneo respecto del socio ${ }^{93}$. Al hilo de esta idea viene a colación la misiva que Pedro IV escribiera al dux Dandolo a finales de julio de 1351 cuando le apuntaba que, aunque nada se dispuso en la alianza establecida entre ellos contra Génova, naves aragonesas se habían apoderado de una serie de plazas en las islas de Córcega y Cerdeña, territorios que pertenecían a la Corona de Aragón aunque rebeldes y que como tales no estaba obligado a ofrecerle información alguna sobre esas operaciones, aunque lo haría a través del embajador veneciano ${ }^{94}$. O la disputa suscitada en agosto de 1354 acerca del todavía impago de parte de las naves armadas producto de los acuerdos de $1351 \mathrm{y}$, sobre todo, el destino de esas embarcaciones: los mares sardos según Pedro IV y el Egeo según la República de San Marcos ${ }^{95}$.

${ }^{92} \mathrm{G}$. Meloni refiere que en el cruce de misivas entre el Común veneciano y Giovanni Steno, embajador ante Pedro IV, previo a la firma de la alianza, la señoría apunta a su legado que una de las cuestiones irrenunciables para los intereses de la República era que la flota catalana pudiese navegar junto a la veneciana en los mares de Oriente en el caso de que los genoveses accediesen a esas aguas, estableciendo como línea divisoria del Mediterráneo el paralelo de Messina. Giuseppe MELONI, Genova e Aragona, p. 65.

${ }^{93}$ Para el caso veneciano cf. Giuseppe Meloni, Genova e Aragona, p. 120.

94" Dux egregie, licet in pactis super liga inter nos et vos adinvicem inita condicionis noviter et firmatis de subscriptis mencio aliqua minime habeatur. Attamen vestram volumus nobilitatem latere quod sicut clare nobis constat inter nobilem et dilectum consiliarium Bernardum de Capraria, por parte nostra, et dilectum nobilem Johannem Steno, nuncium et ambassatorem vestrum ad nostram presenciam destinatum pro parte vestra, condictum extitit verbotenus et comprehensum quod ubi nostra armata castra aliqua sive loca Sardinie vel Corsice insule caperet vel sibi subiceret. Que siquidem castra seu loca ad nos nostrumqque dominium, de iure vel aliter, pertineant seu spectent eadem nobis adquisita nostroque aplicata dominio haberetur, sic quod de eis partem, vobis vel vestro Comuni seu cuivis alii, facere minime teneremur... ". ACA, C, reg. 556, f. 59r. (1351, julio, 30). El primero de junio de ese año Pedro IV comunicaba a los catalanes de Romania el deseo de enviar a Cerdeña una flota para sofocar la revuelta insular, apuntándoles "quorum locorum adquisicio legitime ad nos spectat, prout toti mundo existit notorium, ex concessione per sedem apostolicam nobis seu illustribus predecessoribus nostris facta". Antoni RUBió I LLUCH, Diplomatari ..., doc. CXCIX.

95 "Il momento di frizione giunse quando, nell'estate -1354-, l'armata veneziana, forte di trentatrè galee al comando del capitano generale Nicolò Pisani, uscita da Venezia si recò ad Alghero, ove si sapeva que tuta l'armata regia era racolta, per una manifestazione di forza contro la città assediata, ma soprattutto per prendere le diciotto galee previste dal trattato e navigare, assieme ad esse, verso i mari orientali". Giuseppe MELONI, Genova e Aragona, p. 201. Cf. también las pp. siguientes. 


\section{Del EgEO AL TIRRENO: RAZONES DE UN DESENCUENTRO Y EL FINAL DE LA COLABORACIÓN MILITAR}

Comenzamos por el final, esta última idea expresada, el distinto criterio de las partes en el empleo de la flota establecida en los acuerdos de 1351 fue la causa directa de la ruptura de la alianza. Durante el primer lustro de la década de los cincuenta del Trescientos se mantuvo activa la liga militar entre Venecia y la Corona de Aragón en su guerra contra Génova. Lo enconado de las posiciones provocaba que se hiciese oídos sordos a la solicitud papal de alcanzar una paz ${ }^{96}$, no obstante la realidad de unos tiempos difíciles en toda Europa motivados por los estragos de la peste, que se temía afectasen a la armada de la coalición en cuanto a la renovación del elemento humano $^{97}$. La incesante revuelta sarda, alentada y apoyada por los ligures, activó el conflicto en 1353. En esta ocasión fueron los mares de Cerdeña el teatro de las operaciones navales. Pedro IV había solicitado el armado de una gran flota que quedó al mando de Bernat de Cabrera ${ }^{98}$, a la que se unió la escuadra veneciana compuesta por veinte galeras. La batalla de Alguer sí fue un triunfo para la coalición, que obligó a una debilitada Génova a pedir la protección de la vecina Milán ${ }^{99}$. En el reparto del cuantioso botín obtenido en barcos y prisioneros se respetó de forma escrupulosa el capítulo correspon-

${ }^{96}$ Cf. Giuseppe Meloni, Genova e Aragona, pp. 143-144 y 176-177. ACA, C, reg. 557, f. 195r. (1353, septiembre, 29).

${ }^{97}$ Jerónimo ZURITA, Anales ..., VIII, L, p. 226. Para una visión general de la evolución demográfica en el área véneta cf. Maria GINATEMPO y Lucia SANDRI, L'Italia delle città. Il popolamento urbano tra Medioevo e Rinascimento (secoli XIII-XVI), Firenze, 1990, p. 81. Para la Corona de Aragón, Amada LÓPEZ DE MENESES, Documentos acerca de la peste negra en los dominios de la Corona de Aragón, "Estudios de Edad Media de la Corona de Aragón", VI (1956), pp. 292-447. Cfr. el volumen primero del "VIII Congreso de Historia de la Corona de Aragón", II (1969), donde bajo el epígrafe genérico de I. La peste negra de 1348 y sus consecuencias en la Corona de Aragón se recogen trabajos de José MARTínEZ ORTIZ, José María Doñate Sebastiá, José Trenchs Odena, Winfried KüChler, Hanspeter KeRn, Vicente MARTínEZ MORELLÁ, Phillipe WOLFF y Álvaro SANTAMARÍA ARÁNDEZ. Agustín RUBIo VELA, Peste negra, crisis y comportamientos sociales en la España del siglo XIV: la ciudad de Valencia (1348-1401), Granada, 1979. Desde un punto de vista general, Robert S. GOTTFRIED, La muerte negra: desastres naturales y humanos en la Europa medieval, México, 1989.

${ }^{98}$ De una petición inicial de cincuenta galeras, finalmente, según recoge Zurita, quedaron armadas cuarenta y cinco de estas embarcaciones, cuatro leños más cinco naos. Jerónimo ZURITA, Anales, 4, VIII, LII, pp. 231-233.

${ }^{99}$ Crònica de Pere el Cerimoniós, pp. 1116-1117. J. ZuRITA, Anales, 4, VIII, LII, pp. 232236. Para una visión amplia de la cuestión, Giuseppe MELONI, Genova e Aragona, cap. V. 
diente de la liga de 1351, asignándose según los porcentajes allí estipulados ${ }^{100}$. El imperio marítimo, que era la razón de la lucha, como reconociese el mentado cronista aragonés ${ }^{101}$, podía parecer más próximo a las potencias de la coalición, pero si de algo hizo gala Génova fue de una recuperación envidiable. Paganino Doria, el mismo capitán que había sido derrotado en las costas sardas, venció al año siguiente a los venecianos de Nicoló Pisani en el Egeo $^{102}$.

El empecinamiento ligur, apoyado ahora por la poderosa señoría de Milán, obligó a Pedro IV a ordenar el armado de una tercera flota a primeros de 1354 que capitaneada por él mismo, y de nuevo con el apoyo veneciano, se dirigiría a Cerdeña para sofocar la enésima rebelión. Después de varios meses de asedio fue firmada una paz entre el rey de Aragón y los rebeldes sardos a finales de ese año, que hubo de ser ratificada meses después por la poca fiabilidad que proporcionaba el juez de Arborea $^{103}$. Mientras esto sucedía, embajadores de Génova y Venecia sellaban la paz entre ambas potencias en Milán el primero de junio de $1355^{104}$. Tras una guerra que había desgastado inútilmente pingües recursos, las repúblicas italianas decidieron finalizar el conflicto militar respetando los intereses de cada parte en el área del Mar Negro. El Mediterráneo oriental volvía a ser un mar de calma. Pero no el occidental, pues Pedro IV no quedó comprendido en ella. Una vez sellada la paz entre los litigantes italianos, Venecia envió a sus embajadores al rey Ceremonioso para comunicarle los resultados del acuerdo con los ligures y exponerle de parte del duque que si era contento de haber paz con genoveses por tanto tiempo cuanto debía durar la confederación entre él y la señoría de Venecia que sería firme y si no tenía por bien de aceptarla ellos la

100 "Y porque don Bernaldo de Cabrera como almirante y capitán general por su parte y derecho le cabía la mitad de las galeras y prisioneros y la tercera parte era de los venecianos, el rey le mandó dar a razón de mil florines por galera y doscientos por cada un gentil hombre y a quince florines por la otra gente popular. Y a esta cuenta le cupieron por su parte veinte y siete mil ochenta y cuatro florines y medio, que se podía estimar que era en aquellos tiempos una gran riqueza". Ibídem, 4, VIII, LIII, p. 241.

${ }^{101}$ Ibídem, p. 235.

${ }^{102}$ Giuseppe MeLonI, Genova e Aragona all'epoca di Petro il Cerimionioso. II (1355-1360), Padova, 1976, cap. I. Frederic C. LANE, Venize, pp. 178-179.

${ }^{103}$ Crònica de Pere el Cerimoniós, p. 1119 y ss. Jerónimo ZURITA, Anales, 4, VIII, LV-LVIILVIII-LIX-LXII. Cf. Giuseppe MELONI, Genova e Aragona, cap. VI.

${ }^{104}$ Cf. Giuseppe Meloni, Genova e Aragona, II, cap. IV. 
revocarían ${ }^{105}$. La Serenissima cumplía formalmente con lo estipulado en los capítulos de la liga de 1351, mantener como poco la alianza hasta su conclusión, y aunque prometía la revocación del acuerdo con el inveterado enemigo ligur si el amigo aragonés se lo solicitaba, este último extremo se entendía, ahora más que nunca, antes como artificio diplomático que como posibilidad real de ejecución. La realidad era otra bien distinta, pues el hasta entonces aliado deseaba denunciar el acuerdo por él firmado ${ }^{106}$. A Pedro IV el momento de esa paz le pareció especialmente inoportuno, por cuanto podía debilitar sus negociaciones con Mariano de Alborea, caudillo de los rebeldes sardos.

A finales de septiembre de 1355 el acuerdo entre ambas potencias alcanzaba su fin. Cuatro meses antes, recordemos, Venecia y Génova habían regresado a la normalidad diplomática. Avignon, por su parte, trató de concordar a ligures y catalano-aragoneses. Para tal fin se activaron los resortes diplomáticos en todas las Cancillerías culminando con la presencia de Pedro IV en la corte papal para pasar las fiestas navideñas con el santo padre. Pero no se alcanzó nada positivo por lo complejo de la situación, en la que intervenían en diversos grados Génova, Milán y la propia Corona de Aragón focalizando sus intereses territoriales no sólo sobre Cerdeña sino también sobre la vecina Córcega ${ }^{107}$. En este mapa de relaciones internacionales, lo más próximo a los intereses del rey de Aragón era Venecia. Pero la República de San Marcos no estaba dispuesta a sacrificar la paz en Oriente por Pedro IV, quien desde los hechos de Pera ya no servía a sus intereses tras el traslado unilateral del teatro de las posibles operaciones militares a Occidente para atender a los suyos. Ante tal desencuentro, evidenciado en mutuos reproches que apuntaban a la violación del tratado, visualizada en el desastre veneciano de Porto Longo el año anterior, y al impago de las naves estipuladas del lado catalano-aragonés, el pragmatismo de la república italiana le llevó a terminar

\footnotetext{
${ }^{105}$ Ibidem, 4, VIII, LIX, p. 272.

${ }^{106}$ Rafael TASIS I MARCA, La vida, p. 157. Resulta curioso que en las negociaciones de paz propiciadas por Avignon en 1352 la Corona de Aragón y Venecia vinculaban un posible acuerdo con Génova a la aceptación del mismo por parte del aliado. Giuseppe MELONI, Genova e Aragona, pp. 122 y 144.

${ }^{107}$ Jerónimo ZURITA, Anales, 4, VIII, LX, pp. 279-280. Cf. Giuseppe MELONI, Genova e Aragona, II, p. 95 y ss.
} 
su colaboración militar con el Ceremonioso ${ }^{108}$. No obstante, lejos de plantear una ruptura fría, la Serenissima hizo gala de una elegancia diplomática propia de un estado moderno ${ }^{109}$, salvaguardando sus intereses pero sin desentenderse de quien hasta la fecha había sido su aliado. Con ánimo, pues, de zanjar la liga de 1351, el Común de Venecia envió a la corte de Pedro IV a dos embajadores, Giacomo Bragadin y Nicola Falier ${ }^{110}$. El rey de Aragón, sin duda contrariado, no tuvo más remedio que rendirse a la evidencia, nombrando a Gilabert de Centelles, gobernador de Mallorca, como procurador para llevar el peso de las negociaciones. El nombramiento como procurador certum et specialem a Centelles fue expedido el 24 de enero de 1356, recibiendo el oficial mallorquín plena potestad en ese convenio ${ }^{111}$. Las negociaciones fueron muy rápidas, pues si formalmente el delegado aragonés recibía licencia para abrir el fuego diplomático en la fecha arriba apuntada, en poco menos de dos semanas se cerraba el acuerdo. Es de imaginar que el debate entre las partes se centraría en la indemnización veneciana a la Corona de Aragón por la suspensión unilateral de la liga, quedando finalmente estipulada en noventa y nueve mil florines. El texto de la avenencia no indica razones más allá del deseo de finiquitar la alianza, por tanto no sé si esa cantidad refiere tan sólo a la cuantía comprometida para el mantenimiento de la armada hasta la conclusión de la entente, lo razonable, o también alude a algún capítulo compensatorio no explicitado. Tras el acuerdo fue redactado un documento preliminar por Ferrer de Maquerola, notario público. El resultado de las conversaciones en texto escrito fue presentado a Pedro IV, quien el 3 de febrero de 1356 lo juraba ante los Evangelios y se comprometía a su observancia por el tiempo que se estipulase, siempre y cuando los venecianos salvasen tal cantidad. El documento de aprobación por parte del rey de Aragón, actuando de testigos Hugo, obispo de Urgell, Bernat de Cabrera, Gilabert de Centelles, Mateu Mercer así como Alcedo de Cremona, escribano y notario ducal, fue enviado a Giovanni Gradenigo, ahora $d u x$, para su

\footnotetext{
${ }^{108} \mathrm{Si}$ bien, como refiere G. Meloni, la paz de junio de 1355 entre las repúblicas italianas "si representava como una pausa senza vincitori nè vinti, piuttosto che come una pace vera e propria". Giuseppe MELONI, Cenni sulle relazioni, p. 133. IDEM, Genova e Aragona, pp. 202203.

${ }^{109}$ Acerca del modelo diplomático veneciano, cf. como ejemplo Carlos DIEHL, Una república de patricios, capítulo V. Constantin ANTONIADE, Les ambassedeurs de Venise au XVI siècle, Madrid, 1984.

${ }^{110}$ Acerca de este personaje como $d u x$ cf. John J. NoRwich, A History, p. 230 y ss.

${ }^{111} \mathrm{ACA}, \mathrm{C}$, reg. 556, f. 67r.-v.
} 
conocimiento y aceptación de idéntica manera ${ }^{112}$. La respuesta veneciana se produjo tres meses después, y como se preveía fue favorable. El $d u x$ aceptó el compromiso económico referido en el acuerdo pactado entre los embajadores de ambas partes, y el 12 de mayo, en el palacio ducal de Venecia, lo juró ante los Evangelios ${ }^{113}$. El proceso de validación del documento fue similar al de 1351: los negociadores alcanzan un punto de acuerdo, Pedro IV lo sanciona, se envía una copia del mismo para ser ratificada por la otra parte, y el texto firmado se devuelve a la Corte aragonesa. Fue otro embajador veneciano, Andrea d'Oltedo, quien portó ante Pedro IV, que se hallaba en Perpignan, el texto del acuerdo firmado por Giovanni Gradenigo. Tras la rúbrica del rey de Aragón, el 8 de julio ${ }^{114}$, se devolvía de nuevo a Venecia el 18 de ese mes ${ }^{115}$. Desde ese instante quedó desactivada formalmente la alianza véneto-aragonesa contra la república ligur ${ }^{116}$.

Pero en ese verano sucedieron acontecimientos que cambiarían el curso de la historia de la península ibérica. Fue precisamente en esos días cuando Francesc de Perellós, un marino catalán contratado por el rey de Francia para hacer guerra a Inglaterra en el Canal de la Mancha, la conocida guerra de los Cien Años, a su paso por las aguas del Golfo de Cádiz capitaneando ocho o nueve galeras, según autores, frente a Sanlúcar de Barrameda, donde Pedro I de Castilla se deleitaba observando la pesca del atún, atrapó dos naves piacentinas cargadas de aceite. Este hecho fue considerado por el rey de Castilla como un insulto a su persona y un atropello a su soberanía, y utilizado como escusa para declarar la guerra a la Corona de Aragón, potencia con la que prácticamente desde que alcanzase el trono en 1350 había mantenido una relación muy tensa ${ }^{117}$. Si bien, hay que hacer observar que la acción de Perellós quedaba plenamente justificada dentro de

${ }^{112} \mathrm{ACA}, \mathrm{C}$, reg. 556, f. 66v.

${ }^{113} \mathrm{ACA}, \mathrm{C}$, reg. 556, ff. 68v.-69r.

${ }^{114} \mathrm{ACA}, \mathrm{C}$, reg. 556, f. 68r.

${ }^{115} \mathrm{ACA}, \mathrm{C}$, reg. 556, f. 69r.

${ }^{116}$ Cf. Giuseppe MELONI, Genova e Aragona, II, pp. 130-131. La compensación económica veneciana por la ruptura de la liga tardaría algunos años en saldarse. María Inés MELERO FERNÁNDEZ, Fondos medievales, regesto 14 a 16.

${ }^{117}$ Acerca de la guerra de los dos Pedros cf. María Teresa FERRER I MALLOL, La frontera meridional valenciana durant la guerra amb Castella dita dels dos Peres, "Pere el Cerimoniós i la seva època", Barcelona, 1989, pp. 245-357. José Vicente CABEZUELO PLIEGO, La guerra de los dos Pedros en las tierras alicantinas, Alicante, 1991. Luis Vicente DíAZ MARTín, Pedro I de Castilla, 1350-1369, Palencia, 1995, pp. 173-273. 
la enemistad entre la Corona de Aragón y los ligures, atendiendo a que Piacenza era por entonces fiel aliada de Génova ${ }^{118}$, que a su vez lo era de Castilla.

El estallido de las hostilidades en la península ibérica, dando lugar a la conocida como guerra de los dos Pedros, produjo un reajuste diplomático de escala continental. El primero en lanzar la voz de alarma fue el papado avignonés, que preocupado por la proliferación de conflictos bélicos entre potencias cristianas, procedió a mediar entre los litigantes para conseguir el cese de las hostilidades. Con Castilla parecía poco probable, pues un papa profrancés no había de alimentar una paz con un rey que había ofendido grandemente a Francia al despreciar a su esposa, una infanta de ese origen, a la que repudió con indiferencia prácticamente en el altar y confinó, siendo el inductor de su muerte poco tiempo después. Pero no lo era tanto con la Corona de Aragón respecto de Génova. A Pedro IV no le pareció mala salida reactivar la acción diplomática con el fin de cerrar con crédito su conflicto con la república ligur para centrarse en el que se abría en la península, sobre todo por el peligro que suponía que castellanos y ligures se uniesen contra él, como terminaría ocurriendo. Recogida una vez más la exhortación de Inocencio VI tendente a establecer una paz con Génova, el rey de Aragón nominaba procuradores plenipotenciarios a quienes desde el año anterior hacían de tales en la corte papal tratando de conseguir el tan anhelado acuerdo, Bernat de Tous y Francesc de Tregurà ${ }^{119}$. Pero en esta ocasión fueron los ligures quienes no aceptaron los términos propuestos. Aun sin paz de por medio, Pedro IV hubo de contemporizar con Génova durante los años de guerra contra Castilla, al no contar con suficientes medios militares para plantearse, sin ayuda, mantener abiertos dos frentes ante rivales tan poderosos. La jerarquía de niveles entre los enemigos del rey de Aragón hizo que la República de San Jorge quedase tras Castilla. El problema corso, fosilizado dentro de la política aragonesa, quedó aletargado durante esos años y con él el instigador genovés, que ahora por motivos estratégicos colaboraba con los castellanos.

Venecia, mientras tanto, aprovechaba la paz para activar su comercio con Oriente. Los intereses particulares prevalecieron sobre los de conjunto. Sin embargo, pese al desencuentro final, algo quedó del espíritu de la alianza.

\footnotetext{
${ }^{118} \mathrm{Cf}$. Pierre RACINE, À propos du binôme Gènes-Plaisance, "Oriente e Occidente tra medioevo ed età moderna", 2, Genova, 1997, pp. 1035-1058.

${ }^{119}$ ACA, C, reg. 557, f.f. 201r.-203r. (1356, septiembre, 20). Se trata de varios documentos idénticos.
} 
Lo demuestra no solo el hecho de que a los dos años de aquel suceso Pedro IV privilegiase a los venecianos con la creación de un consulado en Mallorca ${ }^{120}$, sino que cuando tiempo después se abría un nuevo episodio de enemistad véneto-ligur se activaron las relaciones diplomáticas entre ambas potencias que condujeron a sendos tratados de paz y colaboración, aunque sin la trascendencia del de $1351^{121}$.

${ }^{120}$ Mirella BLASON-BERTON, Brevi note sul consolato veneto delle Baleari (1358-1395), "VIII Congreso de Historia de la Corona de Aragón. II. La Corona de Aragón en el siglo XIV", volumen segundo (1970), pp. 295-313.

${ }^{121}$ Giuseppe MelonI, Genova e Aragona all'epoca di Pietro il Cerimonioso, III (1361-1387), Padova, 1982, cap. VI. María Inés MELERo FERNÁNDEZ, Fondos medievales, regesto 31 (1373, septiembre, 28) y 50 (1377, octubre, 27). 